\title{
THE PATHOLOGY OF ASBESTOSIS WITH REFERENCE TO LUNG FUNCTION
}

\author{
BY \\ BRIAN E. HEARD AND ROGER WILLIAMS \\ From the Departments of Morbid Anatomy and Medicine. Postgraduate Medical School, London
}

(RECEIVED FOR PUBLICATION DECEMBER 30, 1960)

Asbestosis was first described by Murray in 1907. Comprehensive experimental work by Gardner and Cummings (1931), Kettle (1932), Gardner (1940), King, Clegg, and Rae (1946), Vorwald, Durkan, and Pratt (1951), and many others has established the importance of long asbestos fibres in producing pulmonary fibrosis and has demonstrated species differences in susceptibility, the mouse and the dog being relatively resistant. Increased liability to lung cancer was first noted by Lynch and Smith (1935) and is discussed later.

Studies of the human morbid anatomy and histology of asbestosis have concentrated disproportionately on the asbestos body, and for this reason the first object of the present communication is to record some necropsy findings in detail. The second object is to attempt a correlation between clinical and pathological findings, since these six cases represent the deaths so far in a larger series of 40 patients studied clinically by Williams and Hugh-Jones (1960a, 1960b). In four cases, one lung was fixed by perfusion via the bronchi with $20 \%$ formalin at a pressure of 25 to $30 \mathrm{~cm}$. applied continuously for at least 72 hours, i.e., " pressure-fixed," and slices were impregnated with barium sulphate to demonstrate emphysema (Heard, 1958, 1959, and 1960).

\section{CASE Reports}

CASE 1.-A man aged 50, who had worked in the asbestos industry from 1937 to 1955 , was admitted to hospital in June, 1958, following a haemoptysis. He gave a history of shortness of breath on exertion for the past four years. There was also a story of rheumatic fever in childhood, and since 1943 he had suffered from chronic rheumatoid arthritis. For many years he had smoked 20 cigarettes a day. On examination he was a thin, ill man with gross drumstick clubbing of the fingers, numerous crepitations at both lung bases, and signs of mitral stenosis and aortic incompetence but no evidence of cardiac failure. The rheumatoid arthritis was fairly severe, affecting mainly the fingers, wrists, and elbows. His chest radiographs showed an enlarged hilar mass which was presumed to be a carcinoma, although bronchoscopy and sputum examination were negative; there was also evidence of asbestosis with mottling of both lung fields and a shaggy border to the heart. The sputum showed many asbestos bodies.

He deteriorated rapidly, with continuing haemoptysis and evidence of cerebral and skeletal spread, dying on September 29, 1958.

Necropsy.-The body was thin. Both hands showed clubbing and ulnar deviation and there were old rheumatoid nodules at both elbows. The chest measured $20.5 \mathrm{~cm}$. in antero-posterior diameter, $25 \mathrm{~cm}$. laterally, and $72 \mathrm{~cm}$. in circumference. These measurements are within the normal range (Pierce and Ebert, 1958).

Both pleural sacs were completely obliterated by dense fibrous adhesions. The trachea and main bronchi contained a large quantity of blood-stained mucus. The right lung was grossly overweight, $1,370 \mathrm{~g}$. The apical segment of the upper lobe showed two bullae, $1.5 \mathrm{~cm}$. in diameter. The lung was cut unfixed and the cut surface revealed massive oedema. An apical scar near the bullae was not calcified. The centres of many secondary lobules were mildly darkened by dust pigment, but showed only a trace of centrilobular emphysema. All middle lobe bronchi were distended with mucopus and the whole lobe was heavily infected, probably from pressure of secondaries in hilar lymph nodes on the bronchus. The anterior $2 \mathrm{~cm}$. of this lobe showed a dense meshwork of steel-grey fibrous tissue surrounding bronchioles, dilated up to $0.5 \mathrm{~cm}$. diameter. The lower lobe showed some similar areas against the pleura, but the appearances were distorted by a spherical tumour mass, $7 \mathrm{~cm}$. diameter, with a pale-grey, granular cut surface and central necrosis. Microscopically this was a moderately welldifferentiated columnar cell carcinoma of the lung with tubular and papillary patterns (Fig. 1).

The left lung ( 885 g.) was prepared by pressurefixation and the volume was $2,200 \mathrm{ml}$. (lowermost limit of the normal range). An antero-posterior slice was impregnated with barium sulphate. There was honeycombing of a wide subpleural region beginning half-way down the back of the lower lobe and extending down to include the costophrenic angle and 


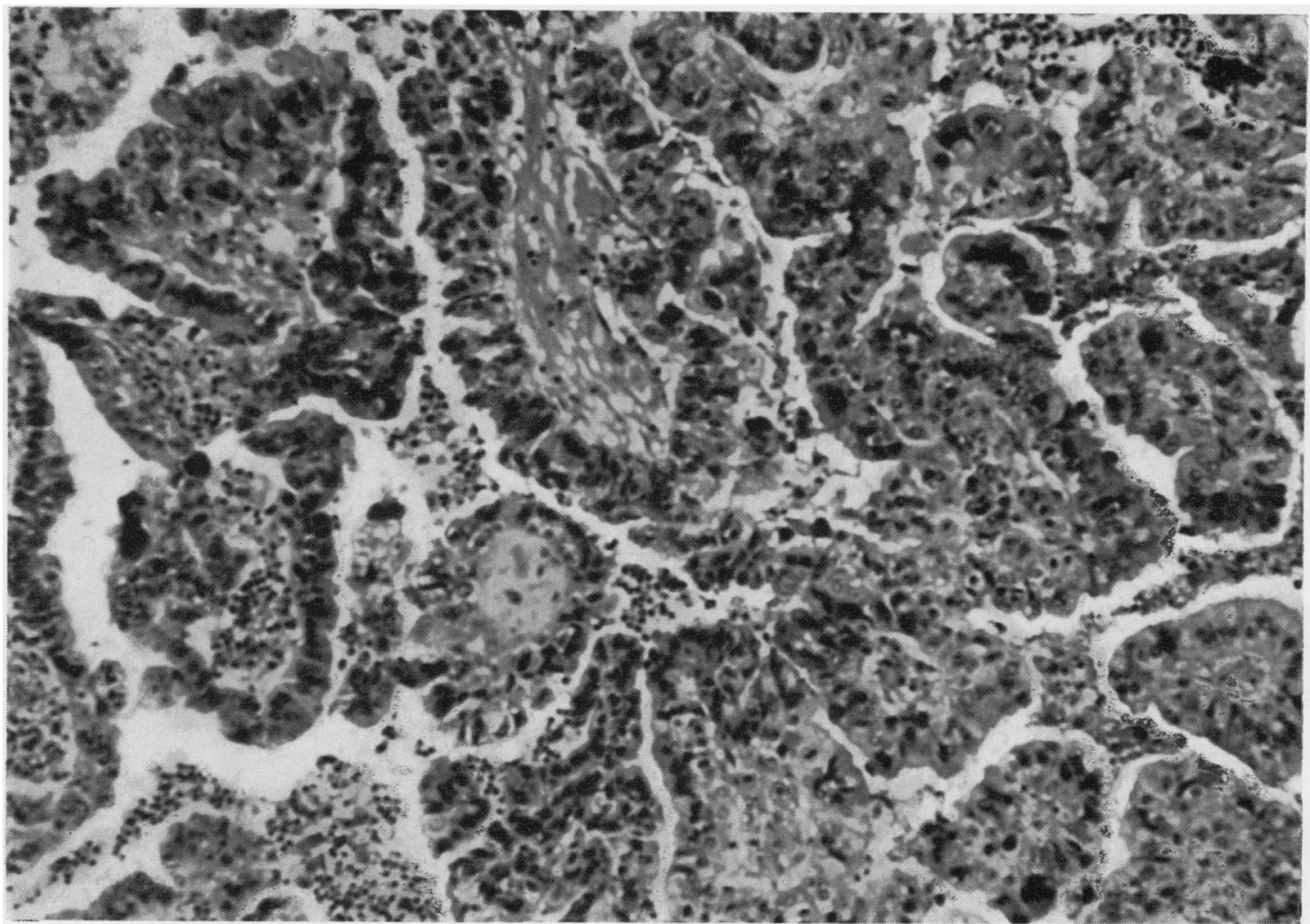

FIG. 1. - Case 1. A moderately well-differentiated columnar cell carcinoma. (Haematoxylin and eosin $\times 150$.)

most of the diaphragmatic surface (Fig. 2). The largest cyst was $1.1 \mathrm{~cm}$. across, but there were many smaller ones, $0.3 \mathrm{~cm}$. diameter or less. The cystic bronchi and bronchioles had fibrous walls and were crossed occasionally by strands or crescents of fibrous tissue (Fig. 3). Between the cysts the lung showed patches of shrinkage and fibrosis and some less affected acinar tissue. There was mucus in a number of the cysts. The anterior part of the lingula and a little of the front part of the anterior segment of the upper lobe were also affected. In the lingula there was one large cystic bronchus, $1.2 \mathrm{~cm}$. diameter, but others were much less than this.

Elsewhere, the left lung showed mild centrilobular emphysema (Fig. 4a). The central zones of the secondary lobules in most areas were marked by very prominent, darkly pigmented, somewhat dilated, respiratory bronchioles crossed by bare strands (pulmonary arteries).

There was no evidence of Caplan's change, as reported by Rickards and Barrett (1958), despite the similar coincidence of rheumatoid arthritis and asbestosis.

The pericardium was obliterated by light fibrous adhesions. There was a plaque of calcification 2 by
1 by $0.2 \mathrm{~cm}$. among the adhesions over the front of the pulmonary conus. The heart weighed $370 \mathrm{~g}$. There was mitral stenosis with a trace of hypertrophy of the left atrium. The valve admitted one and a half finger-tips and showed fibrosis, adhesion of the cusps, straightening of the edges of the cusps. and fibrosis (but no shortening) of the chordae tendineae. The left ventricle was normal $(1.5 \mathrm{~cm}$. thick $)$, but the right ventricle was slightly hypertrophied $(0.4 \mathrm{~mm}$. thick in the outflow pathway). The aortic valve was normal in circumference, but there was slight fibrosis of the cusps and also adhesions at the commissures. Atherosclerosis was moderate in the coronaries and mild in the aorta. The liver (1,630 g.) was slightly increased in weight and had scattered secondary deposits up to $1 \mathrm{~cm}$. diameter and centrilobular congestion. There were secondary deposits in the sternum, ribs, and vertebrae, with a fracture of the middle of the sternum and collapse of the tenth thoracic vertebra. There were also deposits in the adrenals (right $15 \mathrm{~g}$., left $20 \mathrm{~g}$.) and brain (1,285 g.). All other organs appeared normal.

Histology of the Left Lung.-Sections of various bronchi showed a moderate increase in goblet cells in the mucosa and in mucous elements of the glands. 


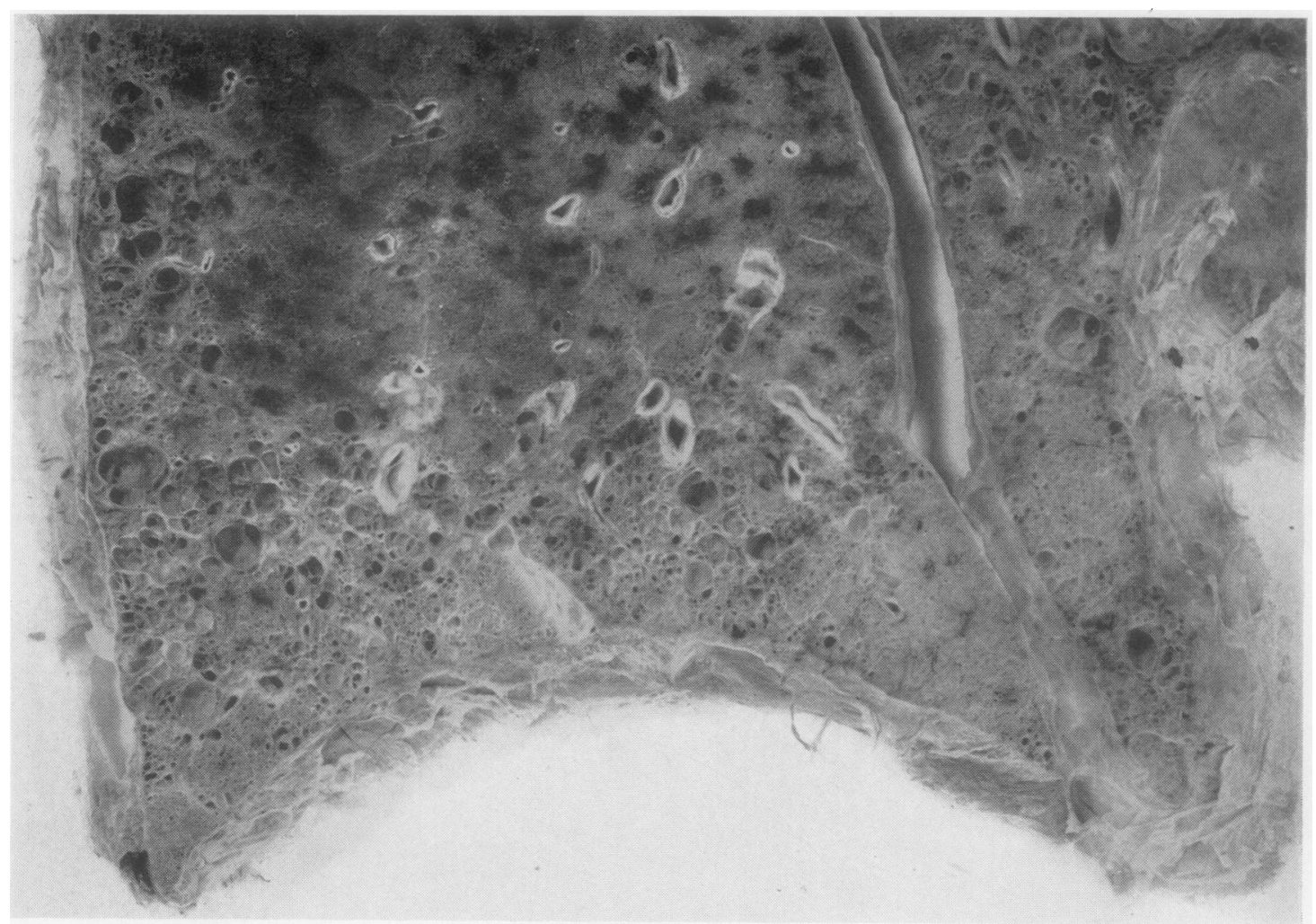

Fig. 2. - Case 1. Honeycombing in a wide subpleural region beginning half-way down the back of the left lower lobe and reaching to the costophrenic angle, over the diaphragmatic surface, and across into the lingula. (Barium-sulphate-impregnation $\times 1 \cdot 1$.)

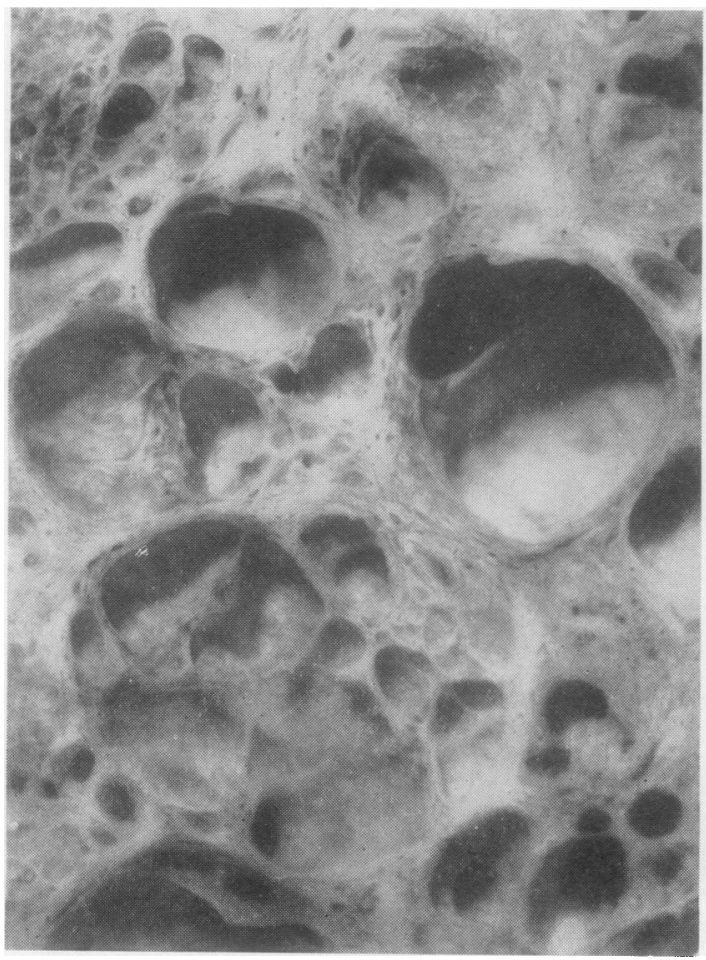

There was also mild acute inflammation of the bronchus to the posterior basal segment of the lower lobe.

Sections of the honeycombed areas of both lobes showed dense fibrous tissue and cystic bronchioles. The latter were sometimes lined by cubical or flattened epithelium, but often this was replaced by a layer of macrophages and multinucleate giant cells. In the lumen, mucin with macrophages was sometimes present, but more frequently there was basophilic, finely granular debris adherent to macrophage-lined walls. In the debris were some neutrophils and macrophages and multinucleate giant cells. Typical asbestos bodies were present (Fig. 5) as well as eosinophilic granular masses with sharp edges. Doubly refractile material was scanty. In the fibrous tissue between the cysts, there were scattered asbestos bodies, together with carbon-laden macrophages, but the asbestos bodies were less plentiful here than in the centrilobular collections elsewhere in the lung. The bodies often presented the characteristic segmented appearance and gave a positive reaction for iron. Most of the fibrous tissue stained for collagen

FIG. 3.-Case 1. A higher magnification of the honeycombing showing fibrosis between dilated bronchioles and almost complete absence of alveoli. (Barium-sulphate-impregnation 5. ) 


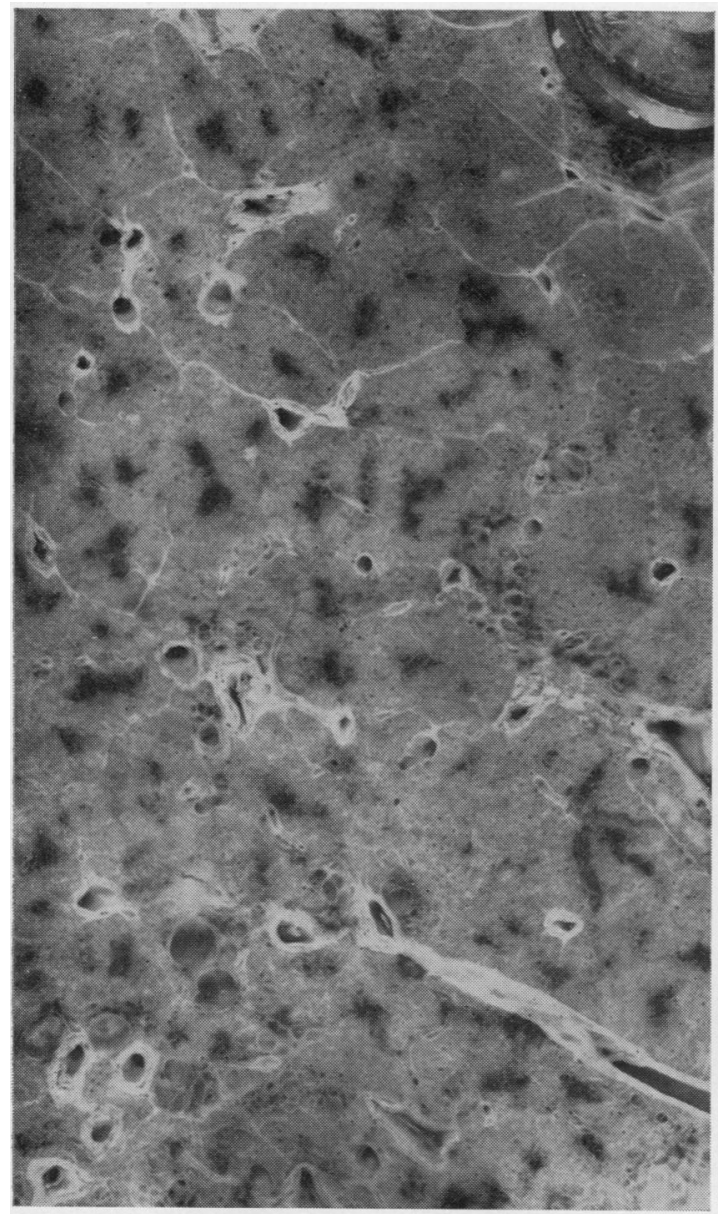

Fig. 4a

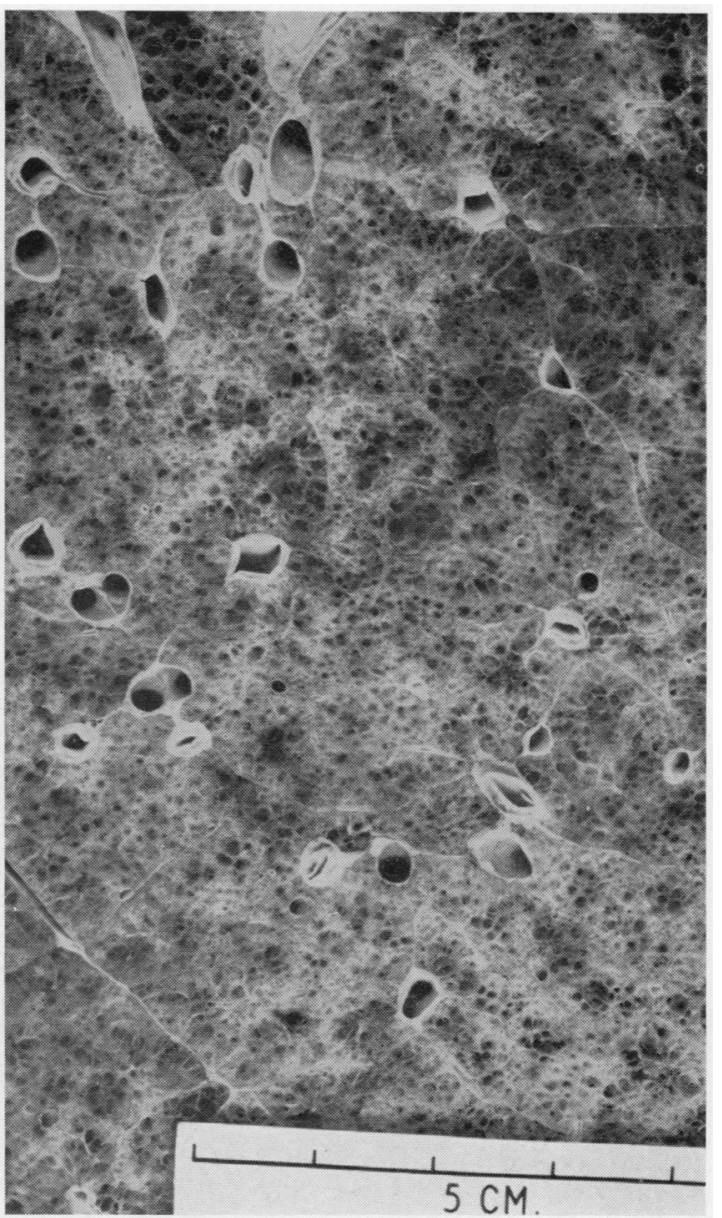

FIG. 4b

FIG. 4 ( $a$ and b).-Comparable regions in the centres of the upper lobes of Cases 1 and 2 ( $4 a$ and $4 b$ respectively) taken at the same magnification $(\times 1 \cdot 2)$. Case 1 (4a) shows mild pigmented centrilobular emphysema, but the surrounding air spaces (pale) are normal. Case 2 (4b), in contrast, shows more dilatation and destruction of bronchioles in most lobules-centrilobular emphysema (see also Figs. 8 and 9). (Barium-sulphate-impregnation $\times 1 \cdot 2$.)

Fig. 5.-Case 1. Typical asbestos bodies with segmented incrustations over asbestos fibres. An uncovered fibre lies in the lower left corner. (Haematoxylin and eosin $\times 700$.)

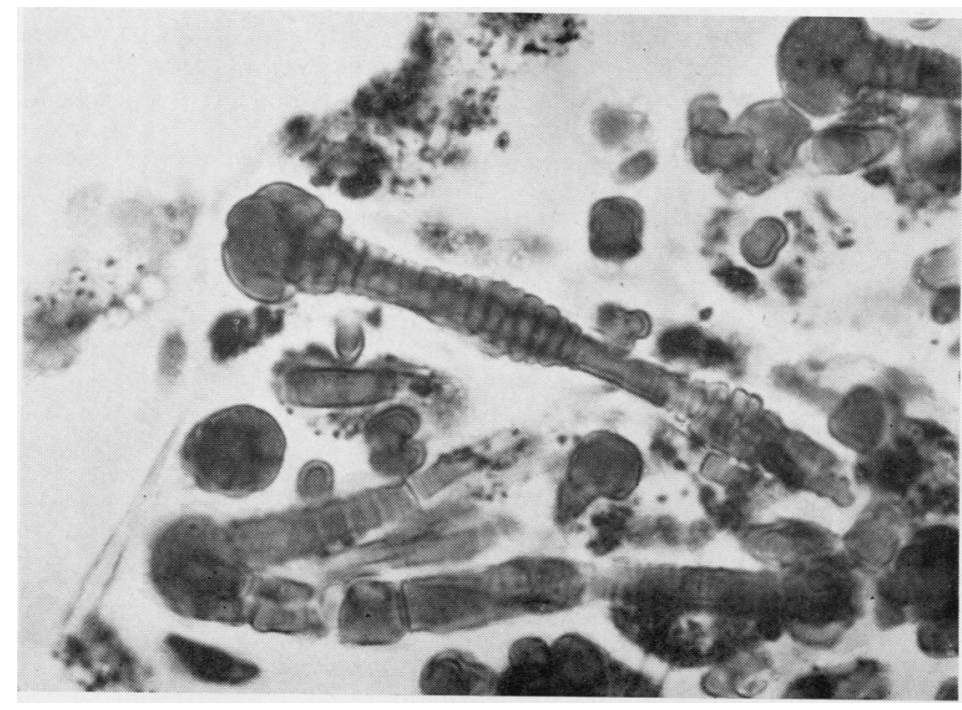

FIG. 5 
rather than reticulin, and there was a mild patchy lymphocytic infiltration. Capillaries were scanty, but arterioles and numerous thin-walled wider blood vessels were present. A small quantity of elastic was present. Some of it lay in scattered small bunches of fibrils and the rest was in blood-vessel walls (Fig. 6). There was no sign of hyperplasia of elastic or smooth muscle. At the pleura the elastic lamina was intact. The pleural thickening outside the lamina was of dense fibrous tissue with some very fine elastic fibrils and fairly numerous thin-walled blood channels and a small number of capillaries. No asbestos bodies were found beyond the elastic lamina of the pleura.

Sections of the upper lobe showed numerous asbestos bodies intimately mixed with carbon-laden phagocytes in the interstices and alveoli of the dilated centrilobular respiratory bronchioles (Fig. 7). Some alveoli were filled with clumps of asbestos bodies. In this case, the slight thickening of bronchiolar walls appeared to be the result of the bulk of foreign material and macrophages rather than fibrosis. Away from the centrilobular zones asbestos bodies and carbon pigment were scanty.

Sections of lymph nodes accompanying large bronchi were searched for asbestos bodies. They were found in small numbers along with occasional small multinucleate giant cells in nodes draining the upper lobe.

CASE 2.-This man, aged 59, had worked with asbestos from 1942 to 1954 . His chest history dated from the smog of 1952, when he had an acute chest illness with purulent sputum, and was off work for several months. When he returned to the factory he noticed that he was breathless on exertion, and this state has progressed each winter with further attacks of bronchitis accompanied by purulent sputum. When admitted in September, 1958, he was breathless on the slightest exertion, such as putting on his pyjamas or getting in and out of bed.

On examination he was cyanosed, with gross clubbing of fingers and toes. The chest expansion was $\frac{3}{4}$ in. There were showers of crepitations at the lung bases and in the axillae.

His chest radiograph showed diffuse reticular shadowing and minute nodulation throughout both lung fields, which appeared hypertranslucent. Both pulmonary arteries were prominent, and the electrocardiogram showed definite evidence of right auricular and ventricular hypertrophy. There were no asbestos bodies in the sputum. The arterial oxygen saturation at rest was $87.5 \%$. In 1959 he was admitted to another hospital with acute abdominal pain and died a few days later, post-mortem examination showing an acute pancreatitis.

Necropsy.-This was performed by Dr. A. Grant, who kindly gave us the following information.

The air passages were not obstructed. The bronchial mucosa was swollen and injected, but no carcinoma was seen. The right lung was covered by numerous adhesions and the cut surface showed some fibrosis, emphysema, and apical bullae.
The heart showed slight left ventricular hypertrophy only. There was a massive chronic gastric ulcer immediately above the pylorus, about 3 in. diameter and penetrating the pancreas deeply and extensively. It communicated with a subphrenic collection of pus, and there were other localized collections between coils of small intestine and in the right iliac fossa. The liver contained a solitary deposit of carcinoma.

Histologically (Dr. K. F. W. Hinson) the pancreas showed a primary carcinoma which appeared to have infiltrated the stomach and metastasized to the liver and the right lung.

Subsequently we received the left lung and prepared it by pressure-fixation and barium impregnation. The pleura showed dense adhesions near the anterior border and lateral aspect of the lingula but elsewhere very few. There were a number of depressed fibrous scars on the medial and lateral aspect of the upper lobe, free of adhesions, and at the back of the lower lobe with an occasional adhesion. There were a few adhesions in the centre of the diaphragmatic surface and between the lobes, but elsewhere the surface was smooth. One notable feature was subpleural fibrosis on the lateral aspect of the anterior halves of the upper lobe and lower lobe, a feature noted in some other cases. A barium-sulphate-impregnated slice showed moderate pigmented centrilobular emphysema of all parts, becoming confluent in the upper third of the upper lobe (Figs, 4b, 8, and 9). In Fig. 4b, a surface photograph of the centre of the upper lobe is compared with a similar area in Case 1 . In most places the emphysema was more severe than here (see Fig. 8), and yet even this area shows far more changes than in Case 1. Fibrosis was prominent in a thin subpleural region in the middle part of the front of the anterior segment of the upper lobe, along the diaphragmatic surface and at the lower two-thirds of the lower lobe pleura. There was a very small patch of moderate diffuse emphysema in the inferior lingular segment.

Histologically the main bronchus to the upper lobe, and that to the posterior basal segment of the lower lobe, showed some hyperplasia of the mucous glands. The latter bronchus also showed terminal acute inflammation of the mucosa. Each subpleural lesion described above showed fibrosis and numerous asbestos bodies and giant cells. There was more fibrosis in the lingula than in the posterior basal segment of the lower lobe. Sections taken from the centres of the lobes away from the subpleural fibrous regions showed advanced centrilobular emphysema, patchy dense interstitial fibrosis, and numerous asbestos bodies.

The lymph nodes showed occasional asbestos bodies up to $25 \mu$ long.

CASE 3.-This 46-year-old man died within a few months of being examined. He had been exposed to asbestos dust in his work from 1930 to 1952, and had a history of increasing breathlessness on exertion since 1946. He was unable to climb more than 12 stairs or keep up with a normal person on the flat. He had 


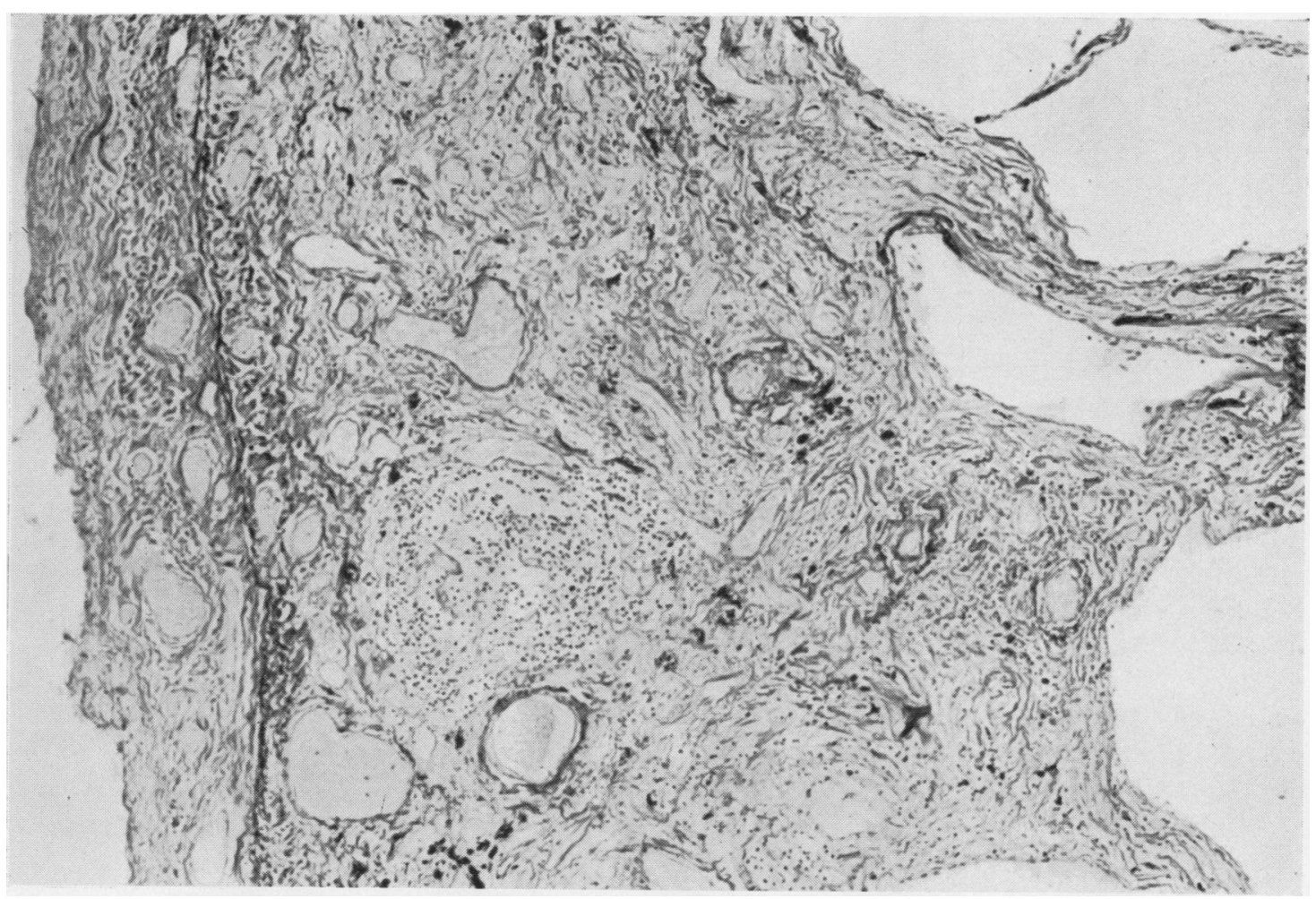

Fig. 6. - Case 1. Fibrosis of lung and pleura showing sparsity of elastic fibres. (Elastic-Van Gieson $\times 110$.)

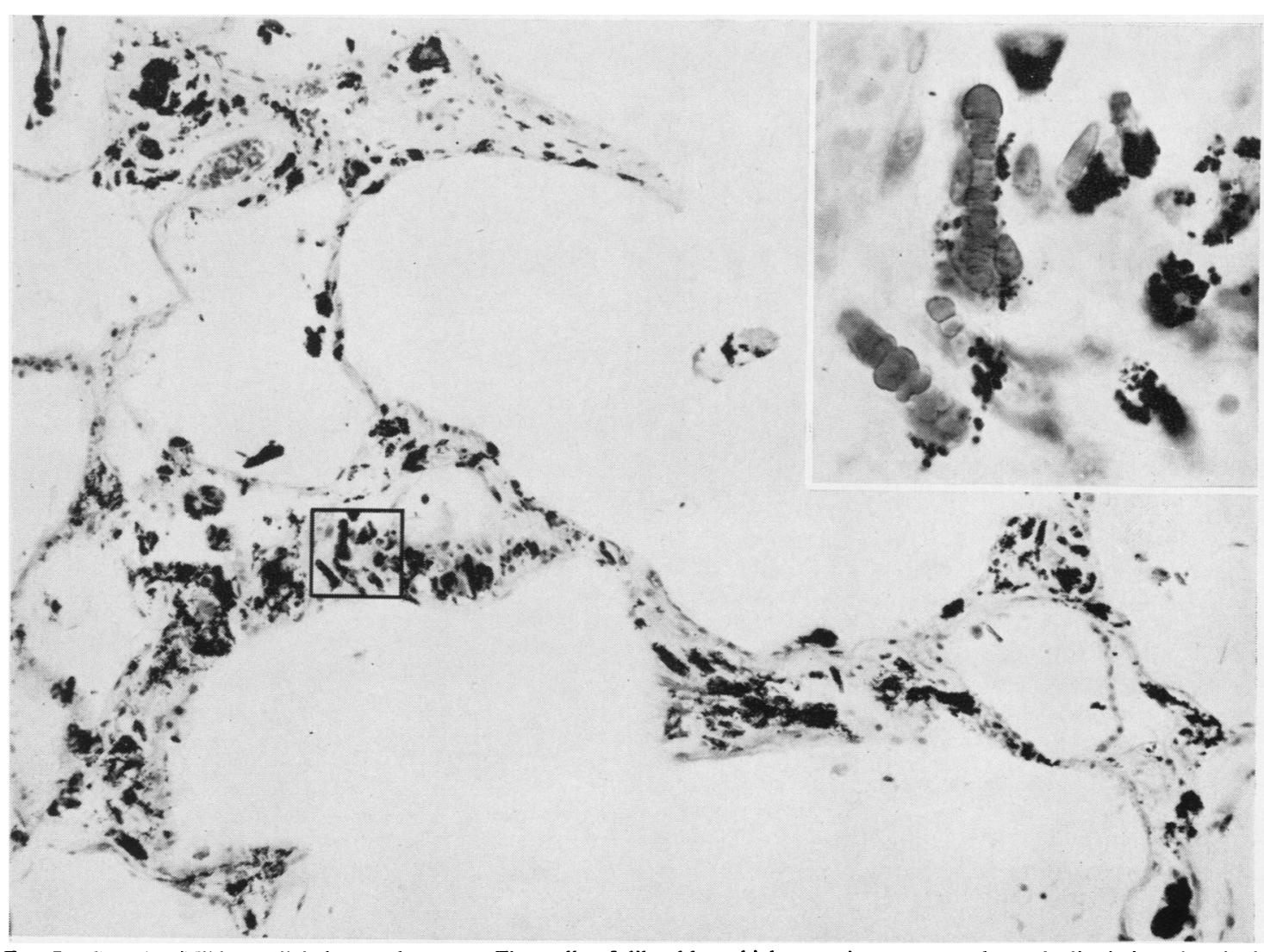

Fig. 7.-Case 1. Mild centrilobular emphysema. The walls of dilated bronchioles contain numerous asbestos bodies intimately mixed with dust-laden phagocytes. (Haematoxylin and eosin $\times 190$.) Inset: Higher magnification of asbestos bodies in square on larger photograph (inset $\times 1,000$ ). 


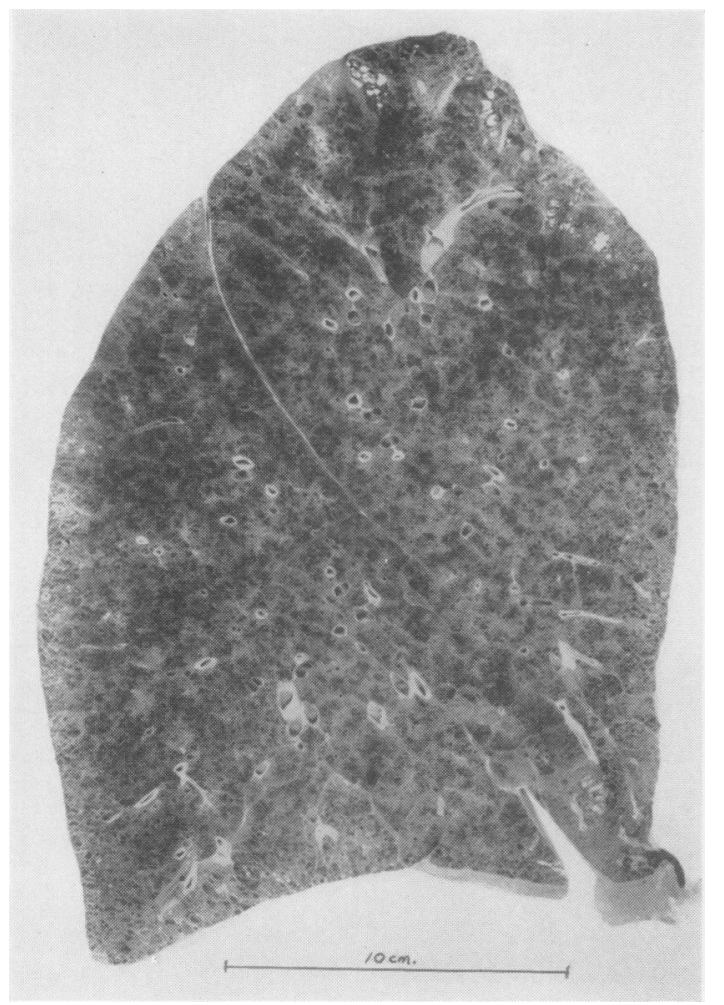

FIG. 8.-Case 2. A lung slice showing widespread centrilobular emphysema and fibrosis in all segments. (See also Figs. 4 and 9.) (Barium-sulphate-impregnated slice.)

a non-productive paroxysmal cough often precipitated by exertion, and for the last two winters had noticed that colds tended to go to his chest. He was admitted in September, 1958, for lung function studies.

On examination he was cyanosed. Fingers and toes were grossly clubbed, and numerous fine metallic crepitations were heard at both lung bases extending round to the front and almost up to the subclavicular regions. There was a marked right ventricular heave in the epigastrium. The chest expansion was $1 \frac{1}{2}$ in.

There were no asbestos bodies in the sputum. The electrocardiogram showed right auricular and right ventricular hypertrophy, the chest radiograph a diffuse mottling throughout the middle and lower lung fields. The arterial oxygen saturation at rest was $84.5 \%$. He died in January, 1959, following influenza.

Necropsy.-This was performed by Dr. A. Grant. who gave us the following information.

No abnormalities were encountered in the brain, peritoneum, stomach, intestines, liver, spleen, or genito-urinary tract. The heart showed dilatation of the right ventricle and hypertrophy of its walls. The valves and coronary arteries were normal. The lungs bulged forwards and completely covered the pericardium. There were dense pericardial adhesions.
The lungs were examined by Dr. K. F. W. Hinson. who gave us the following information.

The pleura was thickened and adherent on both sides, and the interlobar fissures were closed. There was bullous emphysema at the right apex. In the left upper lobe there was some cystic bronchiectasis and emphysema. The cut surfaces, particularly of the lower lobes, were firm and fibrotic.

The cause of death was thought to be cor pulmonale due to emphysema, and pulmonary fibrosis due to asbestosis. We received a portion of the left lower lobe ( 11 by 7 by $3 \mathrm{~cm}$.) from Dr. A. Grant, and it was examined histologically. Cystic spaces up to $0.3 \mathrm{~cm}$. diameter often contained mucus and were lined by numerous goblet cells. Others were lined by flattened epithelium or unlined, and contained occasional giant cells and macrophages. The thick intervening walls were composed largely of very dense collagen, staining brown in the reticulin preparation. Smooth muscle cells were sometimes very plentiful, but lymphocytic infiltration was slight and patchy. Rather more elastic fibres were seen with the collagen than in other cases ; they varied in thickness and were either single

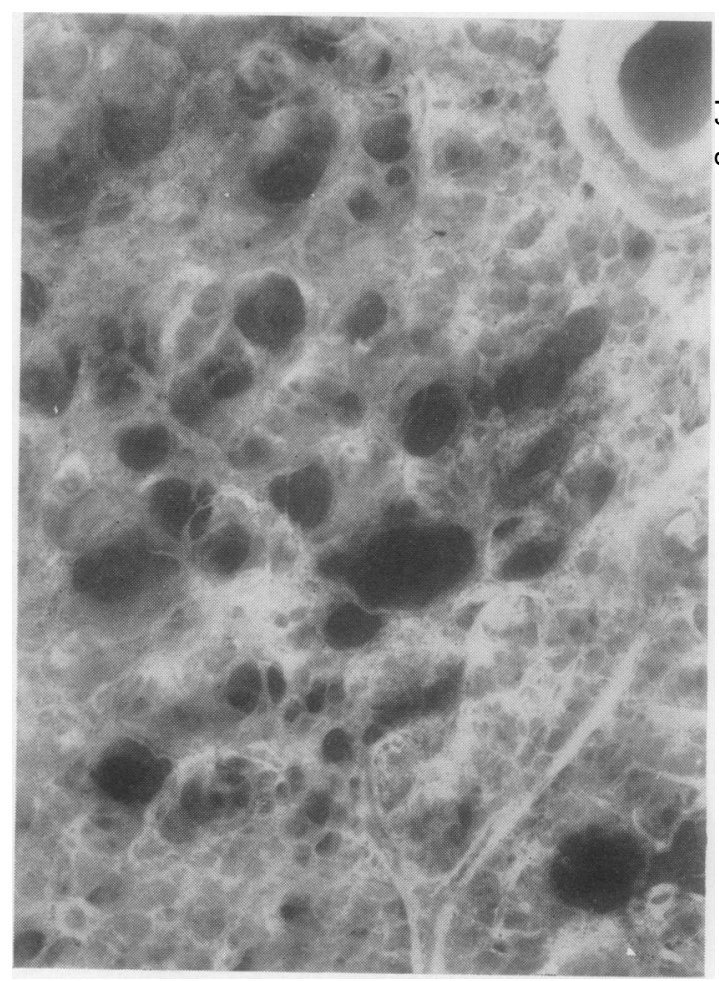

FIG. 9.-Case 2. A higher magnification of the previous specimen showing dilated, fibrous-walled bronchioles occupying the centre of the secondary lobule. Some alvesli persist near the edge (see septum in lower right corner and vein in upper right corner). (Barium-sulphate-impregnated slice $\times 16$.) 
or in small clusters. Elastic persisted in blood vessels. Some asbestos bodies were present. One small collection of surviving alveoli contained fibrin undergoing organization, and this may have been a mechanism contributing to the fibrosis. Arteries showed moderate intimal fibroelastosis in fibrous areas.

CASE 4.--A 54-year-old man had been the works carpenter in the same factory from which the other patients came from 1930 to 1954. Though not actually working with asbestos, he had been employed in many of the dusty departments. He had noticed breathlessness on exertion for about five to 10 years which had slowly progressed. He had an occasional cough but had never had bronchitis. There was a history of indigestion for many years with haematemesis in 1954. He was admitted in October, 1958, for lung function studies.

On examination there were definite signs of the disease, with marked finger clubbing and fine basal crepitations. The chest expansion was 2 in.

The chest radiograph showed mottling in both lower lung fields, right more than left. The electrocardiogram was normal. He was unable to produce an adequate specimen of sputum for examination for asbestos bodies.

He was readmitted on April 13, 1959, with a threemonths history of anorexia, loss of weight, and a persistent aching pain over the right scapula. A chest radiograph now showed widening of the superior mediastinum with a mass lying behind the trachea pushing it forward. The sputum contained poorly differentiated malignant cells. He developed dysphagia and an oesophago-pulmonary fistula, the final cause of death being a perforated peptic ulcer on April 22 .

Necropsy.-Both pleural sacs contained brown turbid fluid (right $200 \mathrm{ml}$., left $100 \mathrm{ml}$.). There were dense adhesions over the lower parts of both lungs, and there were thick dense fibrous plaques, showing traces of calcification, over the diaphragms and in relation to the posterior basal segments. Fig. 10 shows

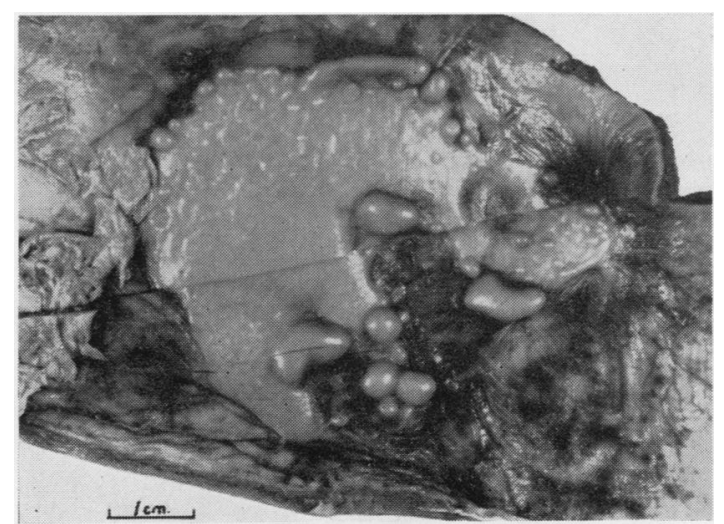

FIG. 10.-Case 4. The upper surface of the diaphragm showing a thick fibrous plaque apparently polished by lung movements. There is some resemblance to a joint surface. one such plaque from the upper aspect of the diaphragm (right side): it reaches $5 \mathrm{~cm}$. maximum diameter and is up to $5 \mathrm{~mm}$. thick. The surface is smooth and shiny, and generally resembles a joint surface: this appearance may be due to polishing movements of the lung, adhesions being absent from the shiny surfaces. There were a few light adhesions elsewhere over the lungs, but the most striking feature was a general pallor of the lung surfaces due to pleural fibrosis. The trachea contained some brown turbid fluid.

The right lung was grossly overweight (1,250 g.). A tumour appeared to arise from the origin of the right main bronchus. It measured $10 \mathrm{~cm}$. diameter and displaced the upper lobe to the right. It was firm and pale, and the cut surface was slightly granular. At the centre it had softened, and a fistulous track passed through it from the oesophagus to the cavitated right upper lobe. The latter showed an infarct $10 \mathrm{~cm}$. diameter with dark grey, foul-smelling contents and ragged walls replacing much of the apical and anterior segments. Thrombi were found in two pulmonary arteries supplying the area. The rest of the upper lobe showed confluent bronchopneumonia, but elsewhere the lung was only congested. There was bronchiectasis in the anterior parts of upper and middle lobes. In the lower lobe was a thin subpleural zone of fibrosis at the back.

The left lung was also overweight (805 g.). It was pressure-fixed, and the volume was then $3,400 \mathrm{ml}$. (normal 2,200-3,500 ml., Izukawa, 1961). The bariumsulphate-impregnated slice showed subpleural fibrosis in patches down the back of the lower lobe, in the costophrenic angle, over the diaphragm, and also at the front of the lingula and anterior segment of the upper lobe. The inferior lingular segment showed more proximal fibrosis and a little bronchiectasis. In the upper part of the upper lobe was slight dilatation of pigmented centrilobular bronchioles, but this was minimal (Fig. 11). There was only a little diffuse (panacinar) emphysema in the anterior parts of both lobes, mostly in the upper lobe. There was bronchopneumonia of the apical segment of the lower lobe.

In the middle third of the oesophagus was an ulcer, 3 by $1.5 \mathrm{~cm}$., communicating by the fistulous track with the right upper lobe. The edges of the ulcer had a punched-out appearance and were not rolled, and the tumour appeared to have arisen in the lung rather than the oesophagus. In the anterior wall of the duodenum was a sutured perforated duodenal ulcer. The rest of the intestines were normal.

The heart weighed $325 \mathrm{~g}$., there was no hypertrophy of the right ventricle, and the valves and other chambers were also normal. The liver and spleen were congested. Lymph nodes near the tumour contained secondary deposits. The genito-urinary tract and central nervous system were normal. The third, fourth, and fifth thoracic vertebrae were invaded by tumour. The prostate was slightly enlarged.

Histology.--The main upper- and lower-lobe bronchi showed hyperplastic mucous glands, but all 


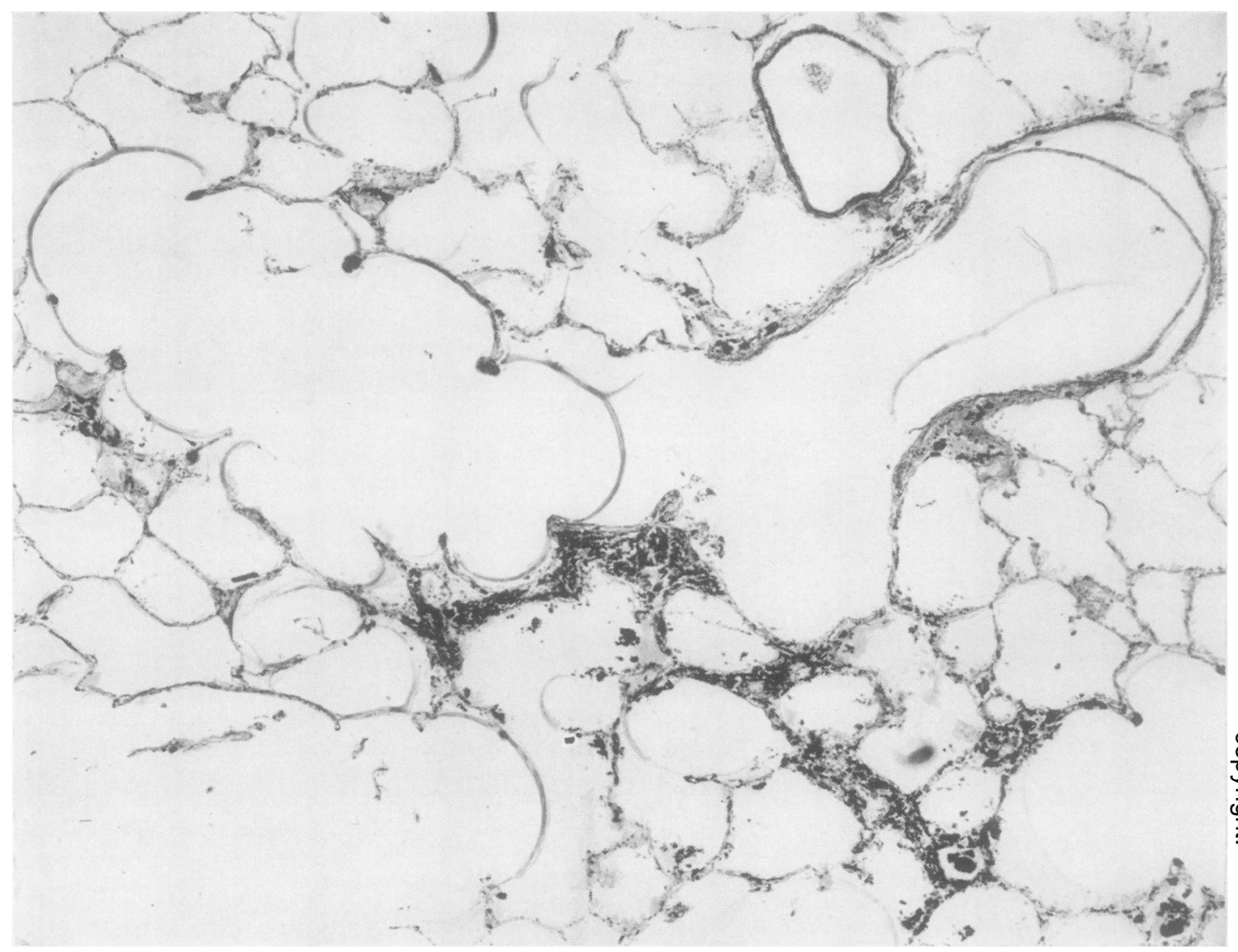

Fig. 11.-Case 4. Slightly dilated centrilobular bronchioles and dust pigment in the upper part of the upper lobe. (Haematoxylin and eosin $\times 52$.)

other parts of the walls were normal. Goblet-cell hyperplasia was confined mostly to fibrosed areas.

Sections of the fibrous lung showed loose connective tissue with abundant collagen but little elastic. The cysts were lined by normal or flattened respiratory epithelium (Fig. 12), and, in places, many goblet cells. The cysts were often filled with mucin. There were no alveoli in the affected areas: Giant cells and asbestos bodies were plentiful.

Elsewhere in the lung were scattered collections of polymorphs, and there was a fibrinous exudate on the pleura. Centrilobular foci of dust pigment showed asbestos bodies but, in reticulin preparations, only a few fibres were visible running between dustfilled phagocytes.

Small arteries (150-400 $\mu$ diameter) in the fibrous areas showed some fibroelastic intimal thickening. Large arteries (except where involved in inflammatory changes in the right upper lobe) and veins were normal. Some small veins showed slight cellular fibroelastic intimal thickening.

A hilar lymph node adjacent to the left main upper lobe bronchus contained occasional asbestos bodies up to $36 \mu$ long (Fig. 13). Macrophages were plentiful in the small sinuses, but only one was seen to have two nuclei. There was a little fibrosis and abundant carbon pigment. The amount of fibrous tissue was not considered more than in most hilar glands.

The bronchial tumour was a squamous-cell carcinoma. Sections of the liver, spleen. kidney, pancreas, and brain showed no abnormality. There was mild benign hypertrophy of the prostate, and in the anterior pituitary was a minute chromophobe adenoma. There was no histological evidence of amyloidosis.

CASE 5.-This man of 45 years had worked with asbestos for 18 months only, from 1937 to 1938 . During this time he developed a cough with some shortness of breath and wheezing which persisted although he left the industry. Radiological changes over the years were minimal until April, 1958, when there was an increase in the shadowing in the right mid-lung field. He was admitted to another hospital, where bronchoscopy was negative, but carcinoma cells were found in the sputum, and so he had a course 


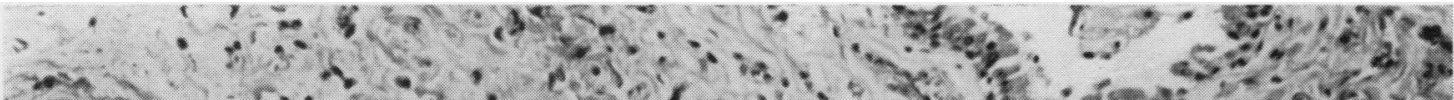
6. ;

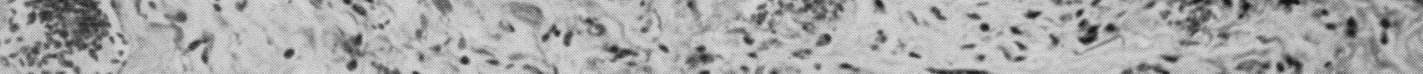

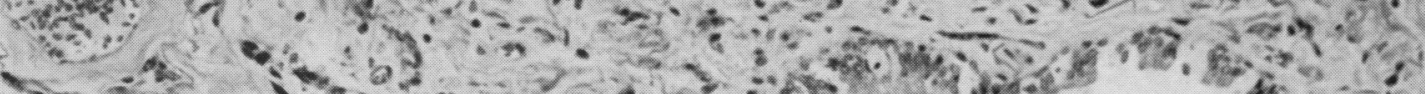

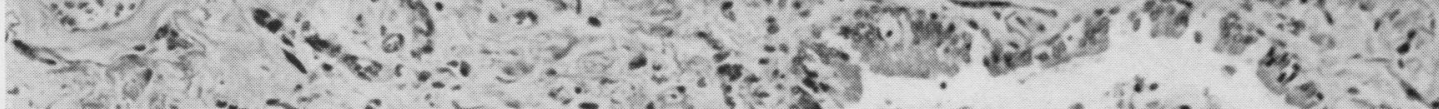

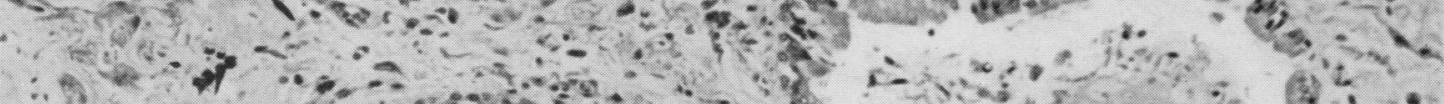

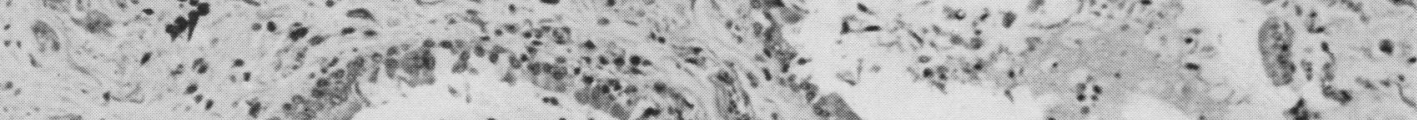

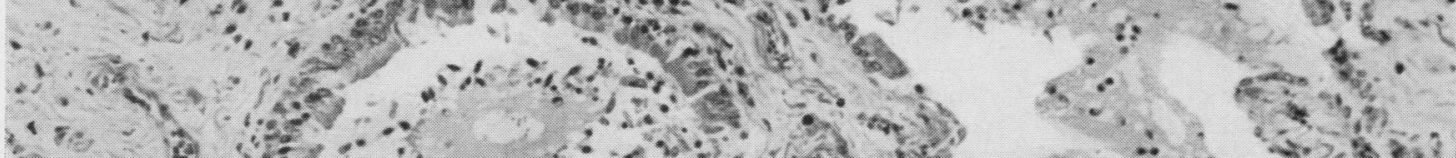

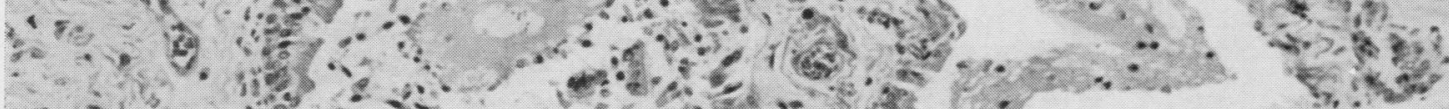

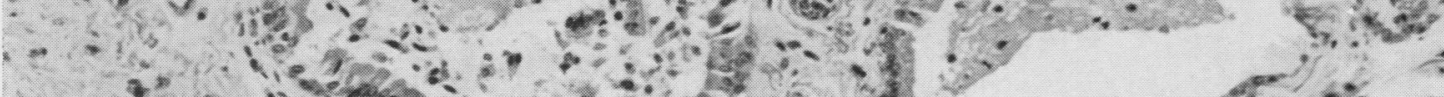

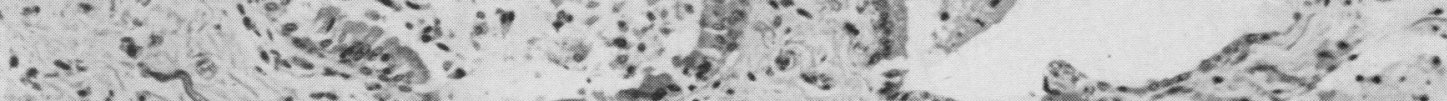

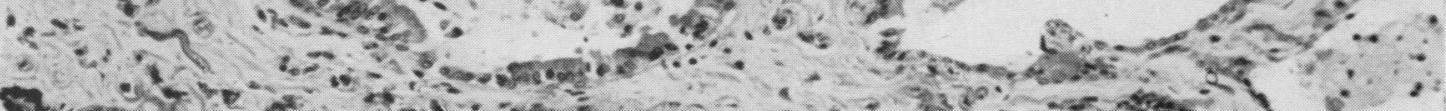

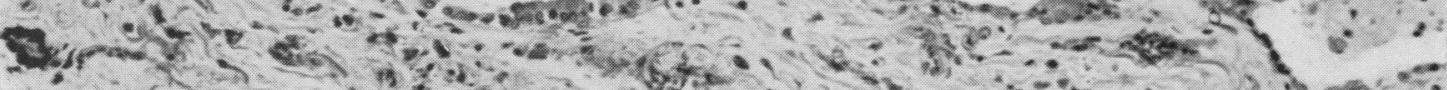

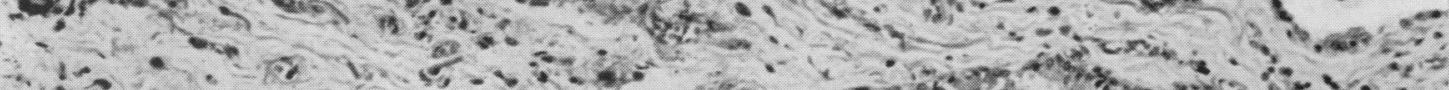
; f.

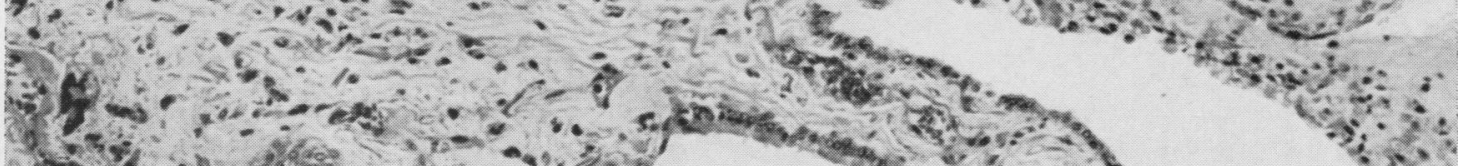
Fig. 12. 4 . Fibrosed lung with dilated bronchioles lined by respiratory epithalium, flattened in places. (Haematoxylin and eosin $\times$ 153.)

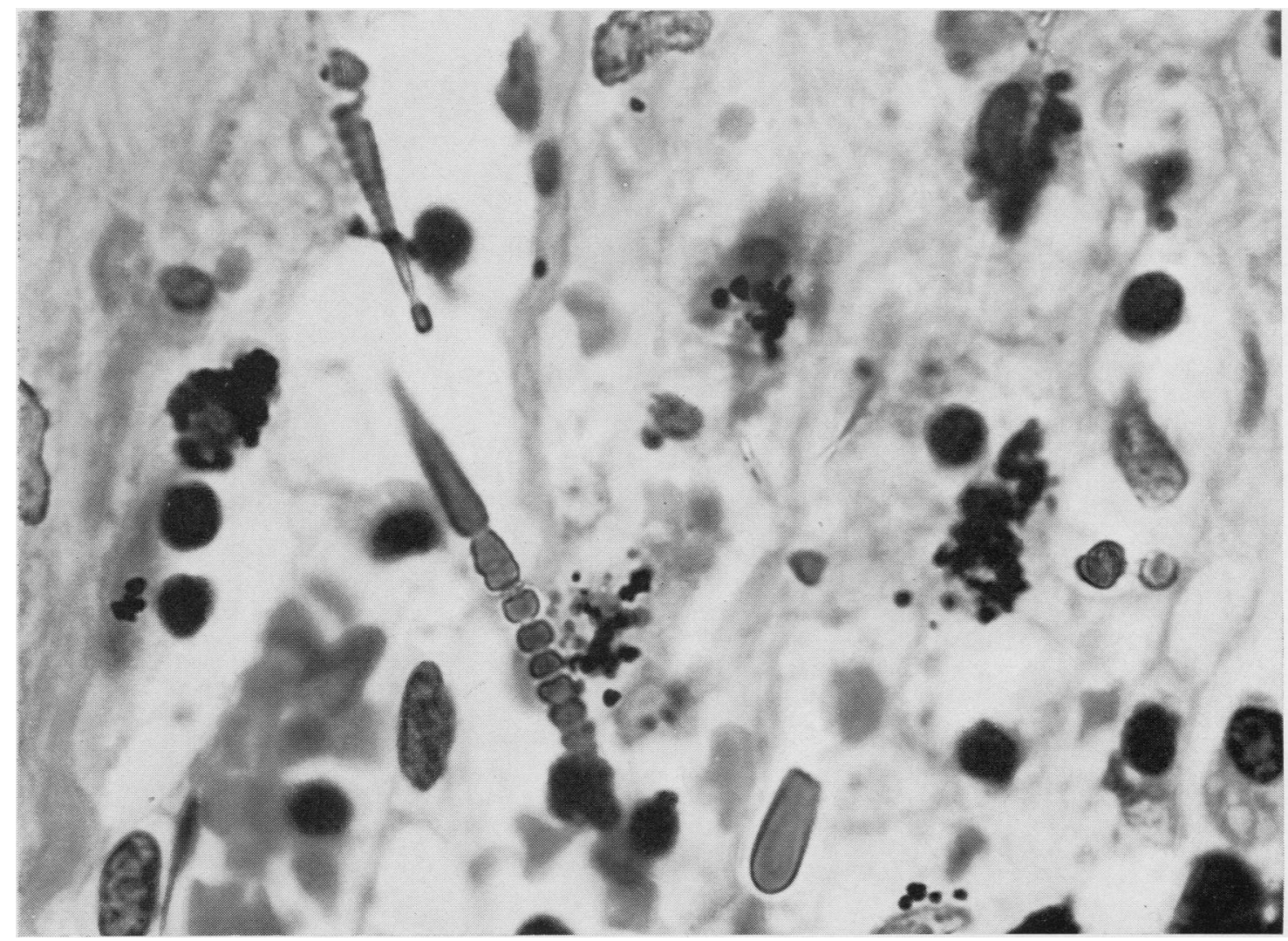

Fig 13.-Case 4. Asbestos bodies up to $36 \mu$ long in a hilar lymph node adjacent to the left main upper lobe bronchus. (Haematoxylin and $\operatorname{eosin} \times 1,700$.) 
of radiotherapy to the right lung. In September he complained of upper abdominal pain. $\mathrm{He}$ was admitted to Hammersmith Hospital in January, 1959.

On examination he was a thin, ill man. There was a large mass in the epigastrium, probably secondaries in the left lobe of the liver. He had no finger clubbing, but there was dullness to percussion and diminished breath sounds in the right axilla with a few coarse crepitations at the right base.

A chest radiograph showed a contracted right upper lobe with fibrotic changes in the right middle lobe and some pleural thickening at the right base. A single asbestos body was found in a 24 -hour specimen of sputum.

He went progressively downhill and died on April 22.

Necropsy.-This was performed by Dr. Keith Simpson, 48 hours after death, who gave us the following information.

The bronchial tree, which was somewhat thickened though not bronchiectatic, was occupied by mucopus and almost completely closed at the stem of the right upper-lobe bronchus by a soft primary carcinoma spreading into this lobe and to regional lymph nodes. Relatively little distinctive fibrosis of either lung was noted, but the pleura on both sides was greatly thickened. A little emphysema was noted at the left apex.

The heart (210 g.) showed brown atrophy, but no sign of cor pulmonale. The stomach, liver, and gallbladder, spleen, and generative organs were normal. The adrenal showed massive tumour deposits (left, 4 by 3 in. ; right, 3 by $3 \frac{1}{2}$ in.).

The left lung was preserved intact for us, filled with formalin. The pleura over the lower lobe and the back and lower lateral surface of the upper lobe was thickened by a remarkable plaque up to $1 \mathrm{~cm}$. thick in parts, which was tightly bound to the lung by dense adhesions. The cut surface showed some tiny centrilobular foci of pigment in the upper parts of both lobes. The bronchioles here did not appear dilated, but, as the lung was not fixed under pressure, dilatation could not be excluded with certainty. The angle of the posterior basal segment was rounded. There was only a trace of fibrosis posteriorly. There was no obvious emphysema (detectable without pressure fixation). A lymph node attached to the anterior segment of the upper lobe contained tumour.

Histology.-The pleural plaque was of devascularized collagen, and no asbestos bodies could be found in it. On the pulmonary side of the plaque there was mild infiltration by lymphocytes and plasma cells. The bronchi to the apical and posterior basal segments showed acute bronchitis but no other lesions. The main lower-lobe bronchus was surrounded by considerable fibrous tissue, possibly due to irradiation or infection. All bronchial mucosa was ciliated. Sections from the lung in the middle of each lobe showed occasional small asbestos bodies among numerous carbon-filled macrophages and no fibrosis. Sections of slight subpleural fibrosis in the posterior basal segment $5 \mathrm{~cm}$. above the costophrenic angle proved to be old localized collapse as shown by collapsed alveolar walls in elastic preparations. The pattern of vessels in this area under low magnification was similar to that in honeycombing (e.g., in Case 4), suggesting that collapse may play a part in the mode of development of honeycomb lung. There was also some dense fibrosis beneath the pleural elastic lamina. Elsewhere there was pulmonary oedema.

Hilar lymph nodes draining the lower lobe contained occasional asbestos bodies up to $60 \mu$ in length, numerous carbon-filled macrophages, and some malignant cells in the peripheral sinuses, but no giant cells.

CASE 6.-This 47-year-old man had no chest symptoms, and was referred for investigation of ascites.

He had worked as a lagger for 32 years, since he was 15 years old. For the past 10 years this had been mainly in an administrative capacity with little exposure to the dust. He was in good health until February, 1959, when he noticed slight swelling of the abdomen which he attributed to "middle-age spread." During April this became very much more marked, and was associated with attacks of stabbing pain mainly in the lower abdomen, though, on occasions, radiating upwards. On admission to Hammersmith Hospital in May, 1959, there was tense ascites with eversion of the umbilicus. There were no othero abnormal findings. The diaphragm appeared high and there were a few coarse crepitations at both bases The fingers were not clubbed.

On investigation the ascitic fluid had a high protein content and contained atypical cells suggestive of adenocarcinoma. All attempts to locate a primary carcinoma failed, barium studies (meal, followthrough, and enema) were normal, and the occult blood tests were negative. Liver biopsy was normal, as were the liver-function tests apart from a low serum albumin and a raised $\alpha_{2} \beta$ pattern on the electrophoretic strip.

Chest radiographs showed a high diaphragm with crowding of the markings in the lower lung fields and later some basal collapse. The sputum contained scanty asbestos bodies. Lung function tests showed a considerably reduced diffusing capacity with a normal F.E.V. $\%$.

At laparotomy on June 18 the peritoneum, omentum, and surface of the liver were studded with small hard nodules. There were indurated plaques in the omentum, one of which was biopsied, but no primary growth was found. Histological examination of the biopsy suggested either a secondary anaplastic carcinoma or a primary mesothelioma of the peritoneum.

The patient was given radioactive gold intraperitoneally, but this had little effect, the peritoneal fluid continuing to form rapidly and necessitating repeated paracenteses. He went slowly downhill, and died at home on December 6, 1959.

Necropsy.-This was performed by Dr. R. D. Swinstead, who gave us the following information. 
The body was emaciated. There was a healed abdominal operation scar, and the abdomen was slightly protuberant. Both pleural sacs were obliterated by dense fibrous adhesions. The heart was small and the pericardium was normal. The myocardium was rather flabby, and no right ventricular hypertrophy was seen. Valves were normal, and coronary arteries showed moderate atherosclerosis. The peritoneal cavity contained some strawcoloured fluid with flecks of fibrin. The omentum was rolled upon itself and heavily infiltrated by hard, slightly nodular tumour. The tumour was also present over the peritoneal surfaces of the stomach, intestines, bladder, spleen, liver, and anterior abdominal wall. The liver $(2,150$ g.) showed tumour on the surface, but was normal internally. The biliary system was normal. The spleen (210 g.) was normal. The pancreas, adrenals, kidneys, ureters, prostate, and testes were normal, as were the stomach and intestines. No enlarged lymph nodes were found, and the sternal marrow cavity was normal.

Further Examination of Respiratory System.-We received the lower part of the trachea and oesophagus and both lungs with visceral pleurae preserved intact. The mucosa of the trachea was congested, but there was no mucus present. The right pleural sac contained $10 \mathrm{ml}$. of blood-stained, slightly turbid effusion. The lung was tightly adherent to the margins of the diaphragm and there were thick fibrous pearly plaques on the diaphragm becoming fused in a number of places similar in appearance to those seen in Case 4 (Fig. 10). There were similar thinner plaques in the parietal pleura over the costal aspect of the lung. Fibrous (and fibrinous) adhesions were present in most areas, being lightest over the lower part of the upper lobe and over the middle lobe. The right lung $(1,110 \mathrm{~g}$.) appeared shrunken, particularly the lower lobe, although the cut surface showed considerable oedema. Scattered through all lobes were small pigmented foci of dilated bronchioles and mild centrilobular emphysema. Around these, especially in the upper lobe, were pale mantles of bronchopneumonia. Bronchi contained only a little mucus and were not congested. The lumina were slightly dilated, especially the middlelobe bronchus, but there was no overt bronchiectasis. The pulmonary arteries appeared normal, and there was no tuberculosis.

The left lung $(1,140 \mathrm{~g}$.) was pressure fixed with the parietal pleura firmly attached to the lower lobe and back of the upper. The volume was $2,520 \mathrm{ml}$., a low figure but inside the normal range (Izukawa, 1961). When the thickened left pleura was dissected back the lower lobe was found to be covered by mesothelioma showing multiple loculi, up to $1 \mathrm{~cm}$. diameter, filled with mucin. There were thick, dense, white plaques on the diaphragmatic surface of the lung adherent to a white nodular plaque on the upper surface of the diaphragm, 10 by $6 \mathrm{~cm}$., like articular cartilage in gross appearance. These were similar to other examples of asbestosis and not due to the tumour. Although the upper lobe was not covered by adhesions (except posteriorly and in the oblique fissure) it presented an unusual opaque external appearance from diffuse subpleural fibrosis. A barium-sulphateimpregnated slice showed small foci of centrilobular emphysema (dilated pigmented respiratory bronchioles) scattered throughout the lung, but the intervening lung was well preserved (no diffuse emphysema). The bronchi were markedly dilated in the lower lingular and basal segments. The tumour behind the lower lobe compressed the lung to some extent, but it was possible to make out a thin zone of subpleural fibrosis at the back of the posterior basal segment of the lower lobe. Added to this was confluent bronchopneumonia of the posterior half of the lower lobe.

Histology of Left Lung.-Sections of various bronchi showed no special features. In hilar lymph nodes there was an occasional asbestos body. The posterior basal segment showed bronchopneumonia and a superficial zone of fibrosis. Surviving air-spaces were sometimes smaller than alveoli and sometimes $1 \mathrm{~mm}$. diameter. They were lined by ciliated columnar epithelium, often partly flattened and deciliated. Some were filled with polymorphs and others contained macrophages, giant cells, and asbestos bodies. The thickest air-space walls were of dense collagen with occasional blood vessels, a few strands of smooth muscle and a few carbon-laden macrophages, asbestos fibres and asbestos bodies, and scanty elastic fibres. This variety probably represented thickened septa rather than alveolar or bronchiolar walls. Thinner walls contained more elastic, probably, in part, remnants from altered alveolar walls but mostly in the walls of blood vessels. There was fibroelastic intimal thickening of small pulmonary arteries in the fibrous regions, and, to a lesser extent, just outside them.

In other parts of the lung the walls of dilated pigmented centrilobular bronchioles showed carbon pigment in macrophages, asbestos fibres, and asbestos bodies. Reticulin fibres were present between these, slightly increased in number.

The dilated bronchi in the lower lobes showed no chronic inflammation. The pleura was invaded by mesothelioma from the peritoneum (Fig. 14). Some of the tumour cells gave a positive reaction for mucin.

\section{Lung-function Tests in All Cases}

The main changes in lung function are shown in Table I. The methods used have already been described (Williams and Hugh-Jones, 1960a). Also shown is the assessment of dyspnoea, which was graded 0-5 according to the criteria of Fletcher (1952).

It can be seen that five of the patients $(1,3,4,5$, and 6 ) showed the functional pattern of a pure diffusion defect with a reduction in the overall diffusing capacity of the lungs associated with hyperventilation and desaturation on exercise, together with a relatively well maintained ventilatory capacity. What reduction there was in maximum breathing capacity was due to a decrease in inspiratory capacity as a result of the pulmonary fibrosis, and there was no evidence of 


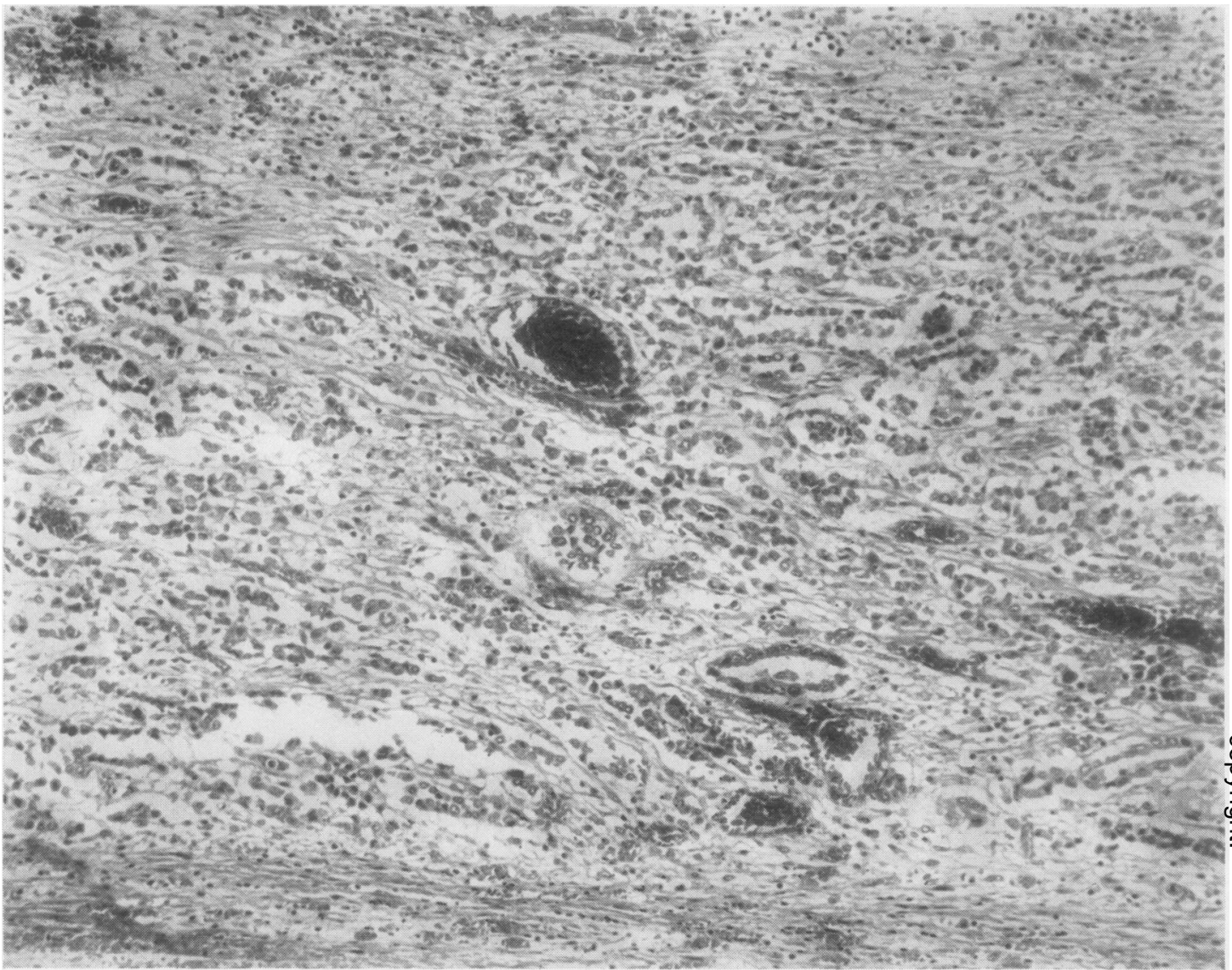

FIG. 14.-Case 6. Mesothelioma thought to have arisen in the peritoneum. A tubular pattern is present in this field. (Haematoxylin and $\operatorname{eosin} \times 160$.)

airways obstruction, the forced expiratory volume (F.E.V. $\%$ ) being within the normal range. The remaining patient (No. 2) showed a different picture with a low F.E.V. \%, which did not increase after the inhalation of a bronchodilator, marked reduction in ventilatory capacity, and considerably increased residual volume, these changes almost certainly being caused by emphysema (see Fig. 4). Unfortunately a satisfactory measurement of the diffusing capacity was not obtained, though it appeared to be very low. It is to be noted also that he was the only patient with grade 5 dyspnoea.

TABLE I

MAIN CHANGES IN LUNG FUNCTION AND GRADE OF DYSPNOEA

\begin{tabular}{|c|c|c|c|c|c|c|c|c|c|}
\hline \multirow{2}{*}{ Case } & \multirow{2}{*}{$\begin{array}{l}\text { M.B.C. } \\
\text { (l. min.) }\end{array}$} & \multirow{2}{*}{$\underset{(\%)}{\text { F.E.V. }}$} & \multirow{2}{*}{$\begin{array}{l}\text { S.V. } \\
\text { (1. } / \text { min.) }\end{array}$} & \multicolumn{5}{|c|}{ Lung Volumes } & \multirow{2}{*}{$\begin{array}{c}\text { Grade } \\
\text { of } \\
\text { Dyspnoea }\end{array}$} \\
\hline & & & & T.L.C. & I.C. & R.V. & R.V. T.L.C. & $\begin{array}{c}\text { Deo }(\mathrm{ml} / \mathrm{min} \\
\mathrm{mm} . \mathrm{Hg})\end{array}$ & \\
\hline $\begin{array}{l}1 \\
2 \\
3 \\
4 \\
5 \\
6\end{array}$ & $\begin{array}{l}53(48 \%) \\
25(25 \%) \\
36(31 \%) \\
92(88 \%) \\
72(62 \%) \\
84(74 \%)\end{array}$ & $\begin{array}{l}75 \\
36 \\
67 \\
69 \\
82 \\
74\end{array}$ & $\begin{array}{l}\overline{46} \\
40 \\
34 \\
- \\
\end{array}$ & $\begin{array}{ll}3.26 & (52 \%) \\
4.49 & (87 \%) \\
3.96 & (65 \%) \\
6.51 & (107 \%) \\
4.32 & (69 \%) \\
5.43 & (84 \%)\end{array}$ & $\begin{array}{ll}1.27 & (43 \%) \\
0.94 & (51 \%) \\
1.13 & (41 \%) \\
2.11 & (77 \%) \\
1.31 & (45 \%) \\
1.59 & (51 \%)\end{array}$ & $\begin{array}{l}1.49(65 \%) \\
2.90(118 \%) \\
2.45(111 \%) \\
2.82(120 \%) \\
2.13(97 \%) \\
2.56 \quad(87 \%)\end{array}$ & $\begin{array}{l}46 \\
65 \\
62 \\
43 \\
49 \\
47\end{array}$ & 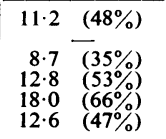 & $\begin{array}{l}4 \\
5 \\
4 \\
3 \\
2 \\
1\end{array}$ \\
\hline
\end{tabular}

M.B.C. = maximum breathing capacity. F.E.V. $\%=$ forced expiratory volume $\%$. S.V.= standardized ventilation. T.L.C. = total lung capacity I.C. = inspiratory capacity. R.V. = residual volume. D Do $_{\text {co }}$ diffusing capacity for carbon monoxide. Percentages in parentheses are of the mid-point of the normal range for that subject. 
TABLE II

PATHOLOGICAL FINDINGS

\begin{tabular}{|c|c|c|c|c|c|c|c|c|}
\hline Case & $\underset{\text { (Years) }}{\text { Exposure }}$ & $\begin{array}{c}\text { Pleural } \\
\text { Adhesions }\end{array}$ & $\begin{array}{l}\text { Pleural } \\
\text { Plaques }\end{array}$ & $\begin{array}{l}\text { Pulmonary } \\
\text { Fibrosis }\end{array}$ & $\begin{array}{c}\text { Centri- } \\
\text { lobular } \\
\text { Emphysema }\end{array}$ & $\begin{array}{c}\text { Diffuse } \\
\text { Emphysema }\end{array}$ & \begin{tabular}{|c|} 
Hypertrophy \\
Right \\
Ventricle
\end{tabular} & Cause of Death \\
\hline $\begin{array}{l}1 * \\
2^{*} \\
3 \\
4^{*} \\
5 \\
6^{*}\end{array}$ & $\begin{array}{r}18 \\
14 \\
22 \\
24 \\
2 \\
22\end{array}$ & $\begin{array}{l}+ \\
+ \\
+ \\
+ \\
+ \\
+\end{array}$ & $\begin{array}{l}- \\
- \\
+ \\
+ \\
+\end{array}$ & $\begin{array}{l}+ \\
+ \\
+ \\
+ \\
\text { tr. } \\
+\end{array}$ & $\begin{array}{l}\text { tr. } \\
++ \\
\text { tr. } \\
\text { tr. }\end{array}$ & $\begin{array}{l}- \\
\text { tr. } \\
+ \\
-\end{array}$ & $\begin{array}{l}\text { tr. } \\
- \\
+ \\
-\end{array}$ & $\begin{array}{l}\text { Carcinoma of lung } \\
\text { Carcinoma of pancreas } \\
\text { Cor pulmonale } \\
\text { Carcinoma of bronchus } \\
\text { Perforated duodenal ulcer } \\
\text { Carcinoma of bronchus } \\
\text { Mesothelioma of the peritoneum }\end{array}$ \\
\hline
\end{tabular}

* Left lung pressure-fixed. Volumes: Case 1,2,200 ml., Case 4, 3,400 ml., Case 6, 2,520 ml.

\section{Discussion}

The main pathological findings have been summarized in Table II. It can be seen there were pleural adhesions in all and thick plaques in three. Gloyne (1933) commented on the frequency of tough adhesions in asbestosis, fusing the two layers of pleura into one fibrous sheet (Wyers, 1949). They were most marked over the lower lobes leading, in advanced cases, to "symphysis pleurae." Gloyne also mentioned that this thickening may become horn like and was likened to cartilage by older writers. Stewart, Tattersall, and Haddow (1932) described a "cake-icing" appearance of the pleura. In the present cases, the diaphragmatic plaques (Fig. 10) had a smooth convex surface resembling articular cartilage grossly, and we suggest that fibrin has been deposited on the diaphragm and organized from beneath while the lung has moved over the surface and polished it. Heard (1953) showed that autogenous fibrin introduced into the pleural sac of the rat had a similar tendency to be organized from the parietal pleura, usually, however, that of the mediastinum. The visceral pleura was only involved if the lung was injured at the time of injection.

It is of interest that careful histological examination of the pleural adhesions and plaques has not revealed any asbestos bodies. None lay beyond the elastic limiting membrane at the junction of lung and pleura. The cause of the adhesions therefore remains to be explained but a hypersensitivity reaction may be responsible. The same problem applies to the mesothelioma of the pleura and peritoneum encountered in some cases of asbestosis.

The trachea and main bronchi showed, apart from terminal acute inflammation, some hyperplasia of the mucous glands as described in chronic bronchitis by Reid (1954). No asbestos bodies were found in the bronchial mucosa or walls in any of these cases. In the fibrosed areas bronchi took part in the cyst formation, being dilated and thick-walled.

Early accounts (Ellman, 1933 ; Merewether, 1933) stressed the occurrence of bronchiectasis. Gloyne (1938) gave a more accurate account of the changes when he described dilated bronchi, but we have not so far encountered " foul bronchiectasis" with fusiform or cavity-like dilatations containing pus. The degree of dilatation of the bronchi can be gauged more accurately in pressure-fixed lungs; our Cases 3, 4. and 6 did show some dilatation.

Asbestos bodies have been studied in great detail by others (e.g., Gloyne, 1932), techniques including electron microscopy (Kühn, 1941 ; Champeix and Bouteville, 1950). Recently, Beattie (1960) has stated that segmentation of the capsule occurs after a lapse of many years (probably not less than 10 years) and later the enclosed fibre fractures precisely in the segmentation planes. The fragments are engulfed by phagocytic cells and in the immediate vicinity of a mass of rapidly broken-down bodies fibrosis occurs. While the fibre is covered by a protein envelope no foreign-body reaction occurs. Our finding of little fibrosis about large collections of bodies in the upper lobes of the present cases is in accord with this. In our cases sections did not show any association between the local concentration of bodies and the degree of fibrosis. Admittedly, some of the largest clumps of bodies were in fibrosed areas, but often they were scanty there and frequent in normal areas of the same lung (see also Clinicopathological Conference, 1960). It is of interest in this connexion that Knox and Beattie (1954a, 1954b, and 1961) analysed the mineral content of lung samples in asbestosis and found no correlation between it and the severity of the lesions. The degree of asbestosis appeared to be correlated more closely with the sum of the years of exposure to dust and the years of survival after the last exposure. These authors consider that a fibrinogenic agent 
may be liberated from the breakdown of asbestos bodies. This would explain our failure to find a local concentration of bodies in fibrosed areas. In our cases, no asbestos bodies were found in the fibrous pleura, even in the horn-like plaques. However, Knox and Beattie (1961) sometimes found substantial quantities of mineral matter here, and suggested that it was due to obstruction to the main intrapulmonary channels and an increased flow in the subpleural plexus. Newer work on the role of hypersensitivity in silicosis (e.g., Powell and Gough, 1959) may also throw light on the mechanism of pleural adhesions which may often be a far more striking feature of asbestosis than pulmonary fibrosis.

In the hilar lymph nodes, asbestos bodies up to $60 \mu$ were found fairly easily. In guinea-pigs, which had been made to inhale asbestos fibres up to $1 \mathrm{~mm}$. long (King's floats) for periods up to 33 months, Vorwald et al. (1951) found asbestos bodies in the lymph nodes. They seldom detected fibrosis in the nodes, and the same can be said about the present cases. We found some macrophages but fibrosis was minimal. Incidentally, the asbestos bodies were in the plane of the section and were not contaminants from adjacent lung.

No asbestos bodies were found in any other organ although they do travel about the body. Stewart, Bucher, and Coleman (1931) described them in the spleen, and Wyss (1953) in the urine.

The pulmonary changes in Case 1 are those of honeycomb lung and we presume that they are caused by asbestosis. However, Dixon and Ball (1957) reported honeycomb lung with rheumatoid arthritis as in this case, and we have recently encountered another case at necropsy. We are therefore unable to exclude rheumatoid arthritis altogether as a cause of honeycombing in Case 1, since honeycomb lung has been seen in a variety of conditions. Oswald and Parkinson (1949) saw examples associated with xanthomatosis, biliary cirrhosis, tuberose sclerosis, and pituitary disorders (see also Cunningham and Parkinson, 1950). Heppleston (1956) had cases associated with eosinophilic granuloma, sarcoidosis, treated tuberculous bronchopneumonia, scleroderma, and interstitial giant-cell pneumonia but 40 of his 53 cases were of unknown nature. Donohue, Laski, Uchida, and Munn (1959) described a familial form. The term has not been applied widely to asbestosis but Lynch (1955) briefly referred to a coarsely honeycombed fibrous texture as his grade 3 of pathological change.

The term "honeycomb lung" only applies to Case 1 in our series, for the fibrosis in the other cases was not associated with comparable cysts. The dilated bronchioles in Case 1 were up to 11 $\mathrm{mm}$. in diameter but in Case 3 they were only $3 \mathrm{~mm}$. maximum diameter and in Case 5 only $1 \mathrm{~mm}$. Fibrosis or honeycombing showed a tendency to be maximal subpleurally and especially in the lower parts of the lung.

The histological appearances of fibrous parts were similar from case to case, the chief lesion being fibrous obliteration of fine air-spaces by collagen with very little reticulin in it. Elastic was scanty and small arteries were often narrowed by fibroelastic intimal thickening. There was no hyperplasia of smooth muscle (Liebow, Loring, and Felton, 1953). The pattern of the smaller blood vessels showed that the changes were based on the original framework of the lung. Dilated surviving air-spaces, mostly bronchioles, were lined by epithelium which was tall or flattened or packed with goblet cells. Often epithelium was replaced by macrophages and giant cells. In the lumen was mucin, neutrophils, eosinophilic, or basophilic granular debris, and asbestos fibres and bodies. Asbestos bodies were more frequent in the spaces than in the walls.

The Presence of Emphysema.-Full descriptions of the diffuse and centrilobular forms of emphysema have been given by McLean (1956), Leopold and Gough (1957), Heard (1958, 1959), and the classification was discussed at a Ciba (1959) guest symposium. In the present cases, diffuse emphysema was slight and localized. There is no reason to attribute it to asbestosis, for it is common in the general population in London. Izukawa (1961), working in this laboratory, found it in 16 out of 50 consecutive male left lungs. Centrilobular emphysema is also common in the general population (Izukawa found it nine times in 50 necropsies), and the lesions in the present cases were examined for a distinctive fibrous reaction to asbestos similar to that described by Vorwald et al. (1951) and others, experimentally, in the terminal bronchioles. In Cases 1, 4, and 6, sections of the mild centrilobular emphysema showed dilated respiratory bronchioles (Fig. 11) and numerous asbestos bodies mixed with carbonladen phagocytes (Fig. 7), but no significant fibrosis in reticulin preparations. The severer lesions in Case 2 were probably inflammatory in origin but asbestos might possibly have contributed here. On the whole, it appears that asbestos plays little or no part in the mild centrilobular emphysema of the present cases which resembles that of the general population. 
BRONCHIECTASIS.-Leathart (1960) has recently demonstrated bronchiectasis bronchographically in six out of 10 cases of asbestosis and attributed clubbing of the fingers to it. $\mathrm{He}$ has suggested that bronchiectasis is more frequent in asbestosis than commonly believed. We found dilatation of bronchi in Cases 3, 4, and 6 and clubbing in Cases $1,2,3$, and 4 . Since other possible causes of clubbing were present, such as tumours, and since patients with bronchiectasis do not always have clubbing of the fingers, the present series is too small to confirm Leathart's suggestion.

Relation with Functional Lesion.-There appeared to be a good correlation between the functional changes detected during life and the findings at necropsy. In the five cases with a predominant diffusing defect (Cases 1, 3, 4, 5, and 6) the pathological changes were those of dense pleural adhesions, variable degrees of pulmonary fibrosis, and little or no emphysema. In Case 2, which in contrast showed definite functional evidence of emphysema, there was severe widespread fine fibrosis and emphysema (Fig. 4b). As stated above, there is a slight possibility that asbestosis was responsible for the changes in Case 2 (numerous asbestos bodies were present), but there was a clear history of recurrent purulent bronchitis differing from those with uncomplicated asbestosis, and chronic infection was probably the chief agent of destruction. Functional evidence of emphysema appears to be rare in asbestosis and was only found in two of the 40 patients described by Williams and Hugh-Jones (1960a).

It is impossible to say whether the restrictive lung lesion with reduced inspiratory capacity and decreased lung volume was due to the presence of pleural adhesions and plaques which were such a marked feature, or whether the pulmonary shrinkage and fibrosis was the more important cause. The reduction in diffusing capacity may be due either to a decrease in the total area of alveolar membrane which is available for diffusion or to a reduction in the permeability of the membrane per unit area, but again probably both factors play a part.

It is to be noted that the first case, with marked honeycombing and cysts up to $1.1 \mathrm{~cm}$. in diameter, had no evidence of expiratory airways obstruction and his residual volume was also within the normal range. Larger cysts may occasionally occur in asbestosis (Williams and Hugh-Jones, $1960 \mathrm{~b}$ ) and the functional pattern is similar to that in Case 1. This is of interest, for Ogilvie and Catterall (1959) found that cases of interstitial fibrosis with marked honeycombing or cystic change tended to have a higher residual volume and functional residual capacity than those without these changes. They suggested that the overinflation of the lung was due to inspiratory traction as they similarly found no evidence of expiratory obstruction. Heppleston (1956) believes that the cystic spaces in honeycombing are due to the excessive inspiratory dilatation of bronchioles adjacent to fibrosed areas, though valvular bronchiolar obstruction may act as a secondary factor in the production of larger cysts.

Williams and Hugh-Jones (1960a) found that changes in the diffusing capacity may be detected at an early stage in asbestosis before there are definite clinical or radiological changes. This is well shown by Case 6, where there were definite areas of fibrosis at necropsy, though some of the reduction in diffusing capacity found during life may have been due to a decrease in lung volume consequent on the high diaphragm. This patient also illustrates the type of disease, with a long exposure and relatively mild fibrosis, which is often seen in men who have worked mainly on lagging and which presumably reflects the low concentration of dust to which they are exposed.

Association With CANCER.-It is to be noted that three of the patients in this series died of lung cancer. Although great care has to be taken in interpreting isolated cases of carcinoma or small series occurring in patients with asbestosis, there seems little doubt now that there is an increased incidence of carcinoma of the lung in this disease. The figures for Great Britain have recently been brought up to date by the Medical Branch of the Factory Inspectorate (McCullough, 1959), who collected particulars of 365 deaths between 1924 and 1955 in which post-mortem examination had confirmed the presence of asbestosis. In 65 of these (nearly 18\%) there was also lung cancer. Doll (1955) concluded that the average risk of cancer of the lung in workers who had been exposed to asbestos dust for twenty years or more was of the order of ten times that experienced by the general population. The majority of the reported series, however, refer to patients in the asbestos textile industry, and some of the findings have been criticized by Braun and Truan (1958), who, in a careful epidemiological survey, found no unusual risk to asbestos miners in the province of Quebec.

Why there should be an increased risk of lung cancer is not known. Experiments with animals have so far shown negative results. Possibly chronic irritation is a factor, for Raeburn and Spencer (1953) found that it was possible to relate 
many peripheral lung cancers to previous scarring and showed that all stages from simple reparative hyperplasia to fully developed lung cancer could be found in association with lung scars. In haematite miners, who also have an increased incidence of lung cancer, the carcinoma usually arises on the periphery in association with areas of dense fibrosis (Faulds, 1957). In 13 cases of lung cancer and asbestosis described by Bonser, Faulds, and Stewart (1955) seven were situated in the periphery and two were pleural. The present series is too small to have significance, but while the tumour in Case 1 (adenocarcinoma) was associated with honeycombing, the tumours in Cases 4 (squamous) and 5 appeared to arise in bronchi. It is to be noted that these were all heavy smokers and were of an age group in which lung cancer is prevalent. The problem of whether a carcinoma can be attributed to the dust exposure is particularly difficult in such patients as our Case 5 , where the exposure occurred many years previously and in whom the clinical and radiological signs were minimal.

The early diagnosis of this complication is particularly difficult radiologically when the growth is situated in the periphery and pulmonary fibrosis is marked. One (Case 4) had in fact been seen and a radiograph taken a few months earlier when there were no signs of the lesion, and his E.S.R. was also normal. Even if the diagnosis is made early any form of curative treatment involving extensive resection or radiotherapy is usually impossible in view of the limited respiratory reserve.

The carcinogenic effect of asbestos may not be confined to the lungs, and this is of importance in connexion with our Case 6, who developed a peritoneal mesothelioma. In the series of Bonser et al. (1955), previously mentioned, there were four cases of peritoneal anaplastic carcinoma in which no primary site could be found. Three of these were females. Keal (1960) also found a high incidence of peritoneal carcinoma in women with asbestosis; during the period 1948-58, 23 women were admitted to the London Hospital with asbestosis; 15 of these have subsequently died, four with carcinoma of the lung, nine with carcinomatosis peritonei ; of the latter, one was certainly ovarian in origin, and this was possibly the primary site in four others, but in the remaining few no primary site could be found.

Primary mesotheliomas of the pleura are now accepted by most writers as distinct entities (e.g., Godwin, 1957; McCaughey, 1958 ; Foster and Ackerman, 1960). They vary from small localized to large diffuse growths, and the latter often involve the whole pleural sac. They also vary in histological appearance, being epithelial, fibrous, or mixed, and this is attributed to an origin from mesoderm. Stout and Murray (1942) found tubular and fibroblastic formations in a tissue culture preparation of a mesothelioma. Godwin (1957) was confident that his sections showed a transition from epithelial cells to fibrous stroma.

Wagner, Sleggs, and Marchand (1960) have recently published from South Africa a remarkable collection of 33 diffuse pleural mesotheliomas, all but one with a probable exposure to asbestos (crocidolite). Previously only occasional cases had been associated with asbestosis (e.g., Cartier, 1952 ; van der Schoot, 1958).

Mesotheliomas of the peritoneum appear to be less common. Winslow and Taylor (1960) found 13 examples in the literature and reported another 12 of their own. In three out of 12 there was direct extension of growth through the diaphragm to involve the pleura, as in our Case 6 . McCaughey (1958) noted that they reproduce to a considerable extent the characteristics of those in the pleura. None of the authors describes a peritoneal mesothelioma in asbestosis.

\section{SUMMARY}

Six patients with asbestosis have been examined clinically and pathologically, particularly for emphysema. In five of them with a predominantly diffusing defect functionally there was little or no emphysema ; there were dense pleural adhesions, sometimes with thick cartilage-like plaques, and variable degrees of pulmonary fibrosis (especially in the lower lobes, subpleurally). In one case, however, with definite functional evidence of emphysema there was widespread centrilobular emphysema pathologically, accompanied by fine fibrosis. Functional evidence of emphysema is rare in asbestosis; this patient's clinical course with recurrent purulent bronchitis differed from the others, and it is thought that the emphysema was associated with infection rather than asbestosis.

The restrictive lung lesion in asbestosis, with reduced inspiratory capacity and decreased lung volume, was probably caused both by pleural adhesions and plaques and by shrinkage from pulmonary fibrosis. The minimal amounts of diffuse and centrilobular emphysema encountered in our other five cases have been seen commonly by us in the general population and are not considered to be caused by asbestosis.

Asbestos bodies were frequent in fibrous and non-fibrous areas of the lungs. Asbestos bodies 
up to $60 \mu$ long were found in small numbers in the hilar glands. None was found in the pleural plaques or in any other organs.

Dense pleural adhesions were found in all six cases and thick cartilage-like plaques in three. The latter sometimes resembled joint surfaces, and it is suggested that organized fibrin deposits were polished by lung movements.

In one case, fibrosis was considerable and an appearance of honeycomb lung produced, with cysts up to $1.1 \mathrm{~cm}$. diameter.

We wish to thank Professor C. V. Harrison, Dr. P. Hugh-Jones, and Dr. W. J. Smither for their advice and Mr. W. Brackenbury for the photographs.

\section{REFERENCES}

Beattie, J. (1960). Unpublished data.

Bonser, G. M., Faulds, J. S., and Stewart, M. J. (1955). Amer. J. clin. Path., 25, 126.

Braun, D. C., and Truan, T. D. (1958). Arch. industr. Hlth, 17, 634.

Cartier, P. (1952). Ibid., 5, 262.

Champeix, J., and Bouteville, J. (1950). Arch. Mal.prof., 11, 607.

Ciba Guest Symposium (1959). Thorax, 14, 286.

Clinicopathological Conference (1960). Brit. med. J., 1, 1345.

Cunningham, G. J., and Parkinson, T. (1950). Thorax, 5, 43.

Dixon, A. St. J., and Ball, J. (1957). Ann. rheum. Dis., 16, 241.

Doll, R. (1955). Brit. J. industr. Med., 12, 81.

Donohue, W. L., Laski, B., Uchida, I., and Munn, J. D. (1959). Pediatrics, 24, 786.

Ellman, P. (1933). J. industr. Hyg., 15, 165.

Faulds, J. S. (1957). J. clin. Path., 10, 187 (August).

Fletcher, C. M. (1952). Proc. roy. Soc. Med., 45, 577.

Foster, E. A., and Ackerman, L. V. (1960). Amer. J. clin. Path., 34, 349.

Gardner, L. U. (1940). J. Amer. med. Ass., 114, 535.

- and Cummings, D. E. (1931). J. industr. Hyg., 13, 65.

Gloyne, S. R. (1932). Lancet, 1, 1351.

- (1933). Tubercle (Lond.), 14, 445.

- (1938). In Silicosis and Asbestosis, p. 245, ed. Lanza, A. J. Oxford Univ. Press, London.

Godwin, M. C. (1957). Cancer, 10, 298.

Heard, B. E. (1953). J. Path. Bact., 66, 359.

- (1958). Thorax, 13, 136.
Heard B. E. (1959). Thorax, 14, 58.

(1960). Amer. Rev. resp. Dis., 82, 792.

Heppleston, A. G. (1956). Thorax, 11, 77.

Izukawa, J. (1961). Personal communication.

Keal, E. E. (1960). Lancet, 2, 1211.

Kettle, E. H. (1932). J. Path. Bact., 35, 395.

King, E. J., Clegg, J. W., and Rae, V. M. (1946). Thorax, 1, 188.

Knox, J. F., and Beattie, J. (1954a). A.M.A. Arch. industr. Hyg., 10, 23.

(1954b). Ibid., 10, 30.

(1961). Personal communication.

Kühn, J. (1941). Arch. Gewerbepath. Gewerbehyg., 10, 473.

Leathart, G. L. (1960). Brit. J. industr. Med., 17, 213.

Leopold, J. G., and Gough, J. (1957). Thorax, 12, 219.

Liebow, A. A., Loring, W. E., and Felton, W. L. (1953). Amer. J. Path., 29, 885.

Lynch, K. M. (1955). A.M.A. Arch. industr. Hlth, 11, 185.

$\longrightarrow$ and Smith, W. A. (1935). Amer. J. Cancer, 24, 56.

McCaughey, W. T. E. (1958). J. Path. Bact., 76, 517.

McCullough, T. W. (1959). Annual Report of the Chief Inspector of Factories on Industrial Health for 1958. Cmnd. 811, pp. 33 and 45. H.M.S.O., London.

McLean, K. H. (1956). Aus. Ann. Med., 5, 73.

Merewether, E. R. A. (1933). Tubercle (Lond.), 15, 69, 109; (1934), 15, 152.

Murray, H. M. (1907). Report of the Departmental Committee on Compensation for Industrial Diseases. (Cd. 3495.) Minutes of Compensation for Industrial Diseases.
Evidence, p. 127. H.M.S.O., London.

Ogilvie, C., and Catterall, M. (1959). Thorax, 14, 216.

Oswald, N., and Parkinson, T. (1949). Quart. J. Med., 18, 1.

Pierce, J. A., and Ebert, R. V. (1958). Amer. J. Med., 25, 13.

Powell, D. E. B., and Gough, J. (1959). Brit. J. exp. Path., 40, 40.

Raeburn, C., and Spencer, H. (1953). Thorax, 8, 1.

Reid, L. McA. (1954). Lancet, 1, 275.

Rickards, A. G., and Barrett, G. M. (1958). Thorax, 13, 185.

Schoot, H. C. M. van der (1958). Ned. T. Geneesk., 102, 1125.

Stewart, H. L., Bucher, C. J., and Coleman, E. H. (1931). Arch. Path. (Chicago), 12, 909.

Stewart, M. J., Tattersall, N., and Haddow, A. C. (1932). J. Path. Bact., 35, 737.

Stout, A. P., and Murray, M. R. (1942). Arch. Path. (Chicago), 34, 951.

Vorwald, A. J., Durkan, T. M., and Pratt, P. C. (1951). A.M.A. Arch. industr. Hyg., $3,1$.

Wagner, J. C., Sleggs, C. A., and Marchand, P. (1960). Brit. J. industr. Med., 17, 260.

Williams, R.. and Hugh-Jones, P. (1960a). Thorax, 15, 103. (1960b). Ibid., 15, 109.

Winslow, D. J., and Taylor, H. B. (1960). Cancer, 13, 127.

Wyers, H. (1949). Postgrad. med. J., 25, 631.

Wyss, V. (1953). Rass. Med. industr., 22, 55. 